\title{
THE USE OF COMPUTED TOMOGRAPHY TO DEFINE ZYGOMATIC COMPLEX POSITION
}

Ian M. Furst DDS, FRCD(C)

A thesis submitted in conformity with the requirements for the degree of Master's of Science

Graduate Department of Dentistry

University of Toronto

C Copyright by Ian M. Furst (2000) 
Acquisitions and Bibliographic Services

395 Wellington Street Ottawa ON K1A ON4 Canada
Bibliothèque nationale du Canada

Acquisitions et services bibliographiques

395. rue Wellington Ottawa ON K1A ON4

Canada
The author has granted a nonexclusive licence allowing the National Library of Canada to reproduce, loan, distribute or sell copies of this thesis in microform, paper or electronic formats.
L'auteur a accordé une licence non exclusive permettant à la Bibliothèque nationale du Canada de reproduire, prêter, distribuer ou vendre des copies de cette thèse sous la forme de microfiche/film, de reproduction sur papier ou sur format électronique.

L'auteur conserve la propriété du droit d'auteur qui protège cette thèse. $\mathrm{Ni}$ la thèse ni des extraits substantiels de celle-ci ne doivent être imprimés ou autrement reproduits sans son autorisation. 


\section{ACKNOWLEDGEMENTS}

Dr. James Mahoney of the Division of Plastic \& Reconstructive Surgery at St. Michael's Hospital, Toronto, Canada, developed the original ideas for this project. Drs Michael Pharoah, and Mahoney put in countless hours supervising, editing and motivating me to complete this project. Dr. Peter Austin of the University or Toronto, Department of Statistics completed the complex statistical analysis of the project. Thanks also to Drs Grace Petrikowski, Don Lewis, David Locker and Emile Rosseau for the advice and guidance during the completion of this project. 


\begin{abstract}
The Use of Computed Tomography to Define Zygomatic Complex Position. Ian M. Furst. Master's of Science. Graduate Department of Dentistry. University of Toronto. 2000.

Purpose: To develop and test the reliability of a method to measure the position of the zygomatic complex relative to the cranial base using CT.

Methods: CT images of dry skulls were created including various image errors. Direct skull measurements were compared to CT measurements. A mixed effect analysis of variance model was employed to assess the effect of method of measurement and the effect of each type of error.

Results: A total of 2040 measurements were made. Interobserver variations of $0.02 \pm 0.03 \mathrm{~mm}, 0.5 \pm 0.4 \mathrm{~mm}$ and $0.4 \pm 0.3 \mathrm{~mm}$ were found for 3 different measurements respectively. The difference between dry skull and CT assessment for the three measurements were $1.2 \pm 0.3 \mathrm{~mm}, 0.4 \pm 0.4 \mathrm{~mm}$ and $1.1 \pm 0.5 \mathrm{~mm}$. Other sources of error were not significant. The measurements were not sensitive to gantry angle and skull inclination changes of 10 degrees or less.
\end{abstract}

Conclusions: The findings suggest that three $\mathrm{CT}$ scan measurements were useful in establishing the position of the zygomatic complex, relative to the cranial base. 
REVIEW OF THE LITERATURE $\ldots$

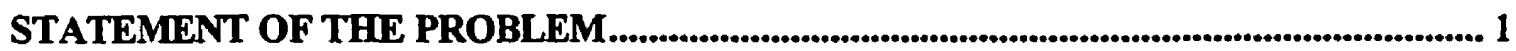

COMPUTED TOMOGRAPY AND FACIAL FRACTURES.......................................... 2

COMPUTED TOMOGRAPHY AND MEASURING DISTANCES ...................................... 4

THE EFFECT OF GANTRY ANGLE ON MEASURING DISTANCES.............................. 7

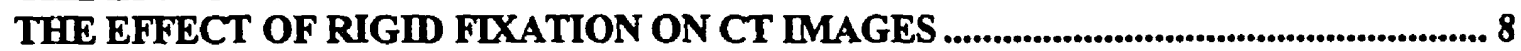

OBSERVER ERROR AND LINEAR MEASUREMENTS ON CT ...................................10

THE ASSESSMENT OF FACIAL SYMIMETRY ................................................................

THE USE OF COMPUTED TOMOGRAPHY TO DEFINE

ZYGOMATIC COMPLEX POSITION _................................................13

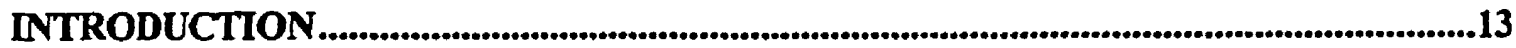

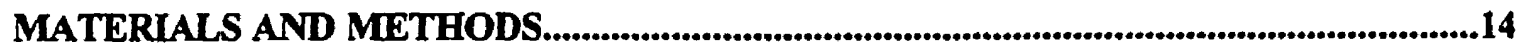

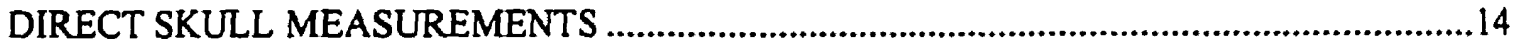

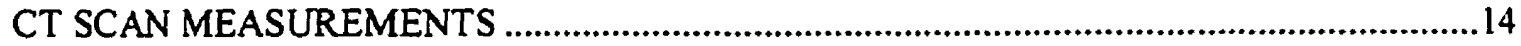

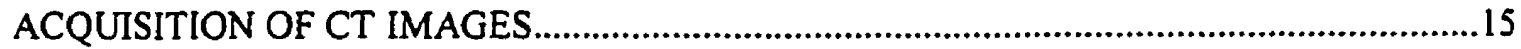

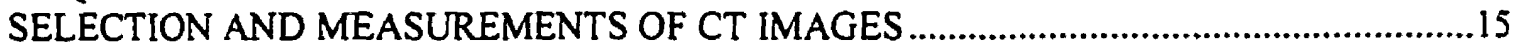

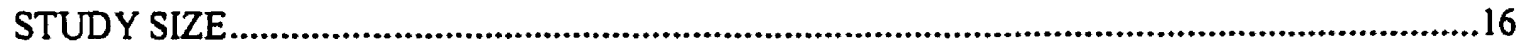



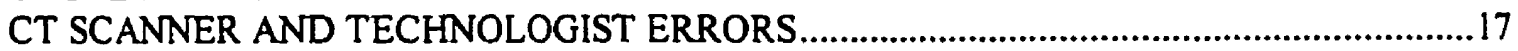

EFFECT OF GANTRY ANGLE AND SKULL INCLINATION .....................................17

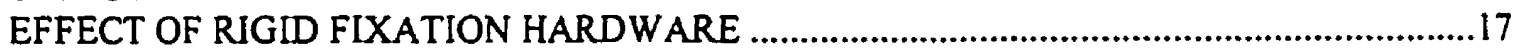

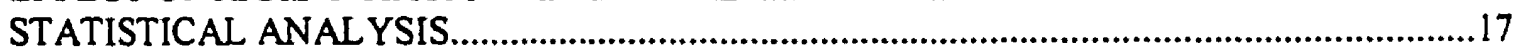

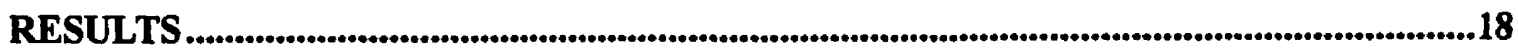

INTEROBSER VER VARIATION

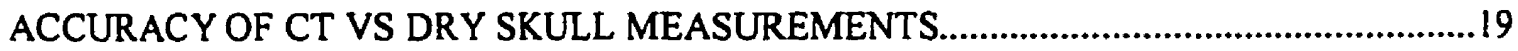

ACCURACY OF CT VS DRY SKULL IN ASSESSING SYMMETRY ..............................19

EFFECT OF INSTRUMENT ERROR

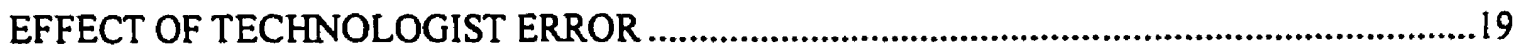

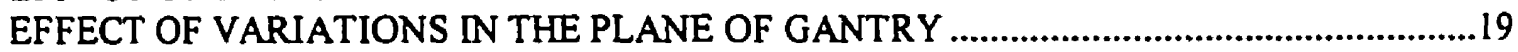

EFFECT OF VARIATIONS IN THE SAGITTAL PLANE OF INCLINATION .......................20



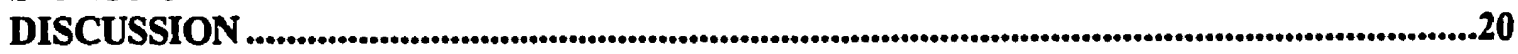

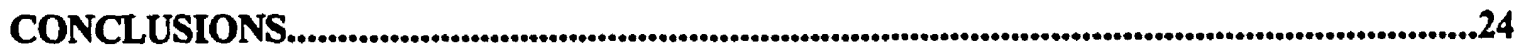

TABLE 1 - DESCRIPTION OF REFERENCE LINES, LANDMARKS AND MEASUREMENTS............26 TABLE 2 - MEAN DIFFERENCES BETWEEN DRY SKULL AND CT MEASUREMENT FOR THE LEFT

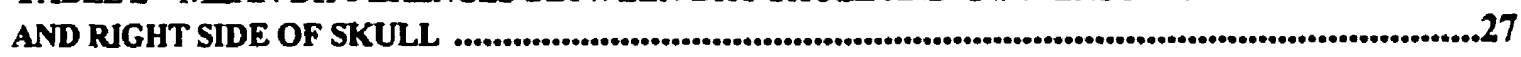

TABLE 3 - MEAN DIFFERENCES IN THE ASSESSMENT OF SYMMETRY BETWEEN DRY SKULL

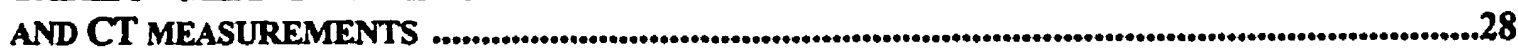

TABLE 4 - MEAN DIFFERENCES IN MEASUREMENTS AFTER REPEATING SCAN IN SAME

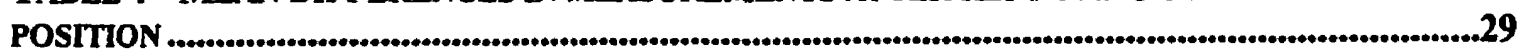

TABLE 5 - MEAN DIFFERENCES IN MEASUREMENTS AFTER REPOSITIONING BY THE CT

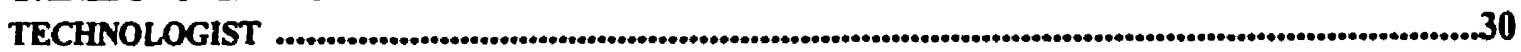

TABLE 6 - MEAN DIFFERENCES IN MEASUREMENTS WITH VARIATIONS IN GANTRY ANGLE ..31 
TABLE 7 - MEAN DIFFERENCES IN MEASUREMENTS WITH VARIATIONS IN SKULL

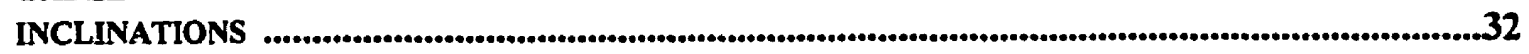

TABLE 8 - MEAN DIFFERENCES IN MEASUREMENTS WITH ADDITION OF A RIGID FIXATION

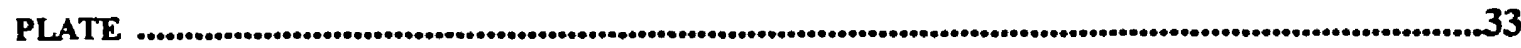

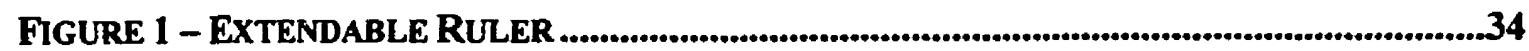

FIGURE 2 - PLASTIC CONTAINER AND MOUNT FOR SKULL IN CT SCANNER ...........................35

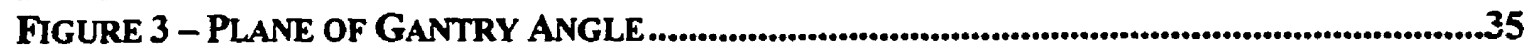

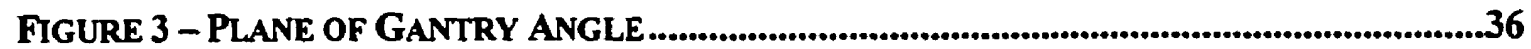

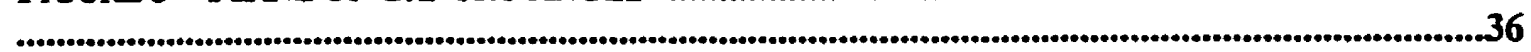

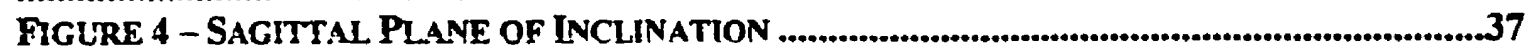

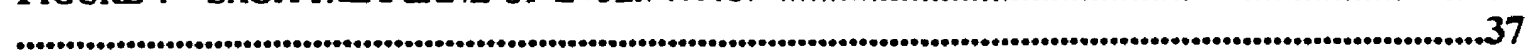

FIGURE 5 - AXIAL CT IMAGE WITH LANDMARKS, REFERENCE LINES AND MEASUREMENTS

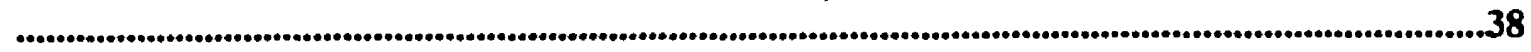

FIGURE 6 - CORONAL CT IMAGE WITH LANDMARKS, REFERENCE LINES AND

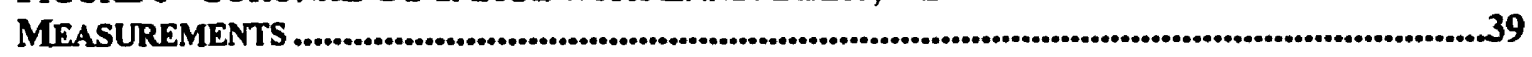

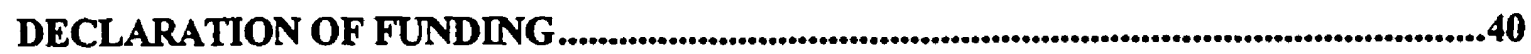

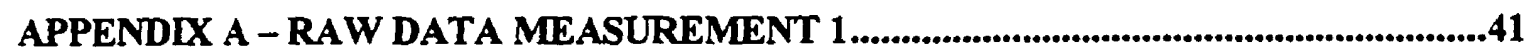

APPENDIX B - RAW DATA MEASUREMENT 2 .....................................................44

APPENDIX C - RAW DATA MEASUREMENT 3 ........................................................47

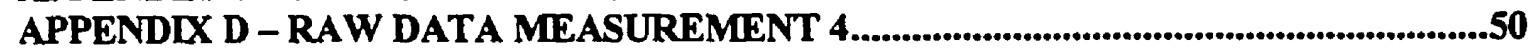

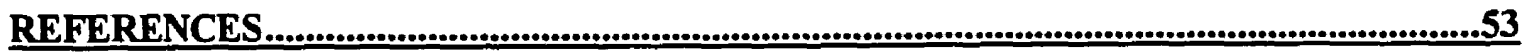




\section{REVIEW OF THE LITERATURE}

\section{STATEMENT OF THE PROBLEM}

In 1901 LeFort published his three-part experiment, which determined the most common lines of facial fracture.' Currently, computed tomography (CT) is the imaging method of choice for assessing complex facial trauma. It has also been used in research to assess treatment outcome by measuring distances to establish the position of various bones of the facial skeleton.

Fracture of the zygomatic complex is one of the most common facial fractures. ${ }^{23.4 .5}$ The zygomatic complex refers to a combination of the zygomatic bone, zygomatic process of maxilla and zygomatic portion of the temporal bone which make up the prominence of the cheek. The zygomatic bone is a roughly four-sided pyramid that articulates with the frontal, sphenoid, maxillary and temporal bones. Due to the thin bones supporting the zygomatic complex, fracture can occur with minimal force. Fracture of the zygomatic complex can result in flattening of the malar prominence and zygomatic arch, deformity of the orbital margin, persistent trismus (due to temporalis muscle injury and edema), abnormal nerve sensibility of the associated nerves, displacement of the palpebral fissure, enopthalmus, and diplopia.

Given the morphologic and functional consequences of zygomatic fracture, many studies have examined ways to reduce and fixate this fracture. The most popular way to reduce zygomatic complex fractures is through the temporal approach, first described by Gillies in $1927^{6}$. Other techniques for reduction include the buccal sulcus approach ${ }^{7}$, eyebrow approach $^{8}$, intrasinus approach, percutaneous approach with bone hook ${ }^{10}$, and towel clip ${ }^{11}$. In addition, various methods of fixation have also been described including maxillary sinus packing $^{12}$, immediate bone grafting ${ }^{13}$, maxillary sinus balloons ${ }^{14}$, transmalar $k$-wires ${ }^{15}$, external fixation devices ${ }^{16,17}$, intraosseous wires ${ }^{18}$ and rigid miniplates ${ }^{19}$.

Two studies have attempted to compare the esthetic and functional results of different treatments using a combination of pre-operative plain radiographs or CT and post-operative manual anthropomometry. ${ }^{20,21}$ These studies have lacked objective parameters to compare 
pre-operative deformity to post-operative results which makes it difficult to apply the results clinically.

To assess the position and the symmetry of the osseous components of the facial skeleton, a reference point is required. A reproducible midline for the cranial base and facial structures would serve as a reference but one has yet to be defined. In addition, a method of assessing the symmetry and position of the zygomatic complex relative to the cranial base has not been developed.

\section{COMPUTED TOMOGRAPY AND FACIAL FRACTURES}

Treatment outcome has been based on the ability of a particular treatment modality to restore normal facial function and morphology. To assess these goals a variety of radiologic and clinical parameters have been used. Some of these parameters, however, are rather subjective and therefore, subject to a higher degree of error. A more reliable method of measurement may be accomplished by using the images produced by $\mathrm{CT}$.

Computed tomography is the imaging modality of choice for assessment of fractures of the facial skeleton. Manson et al ${ }^{22}$ reviewed $4648 \mathrm{CT}$ scans of facial fractures including 243 zygoma fractures. They classified each fracture into either a low, middle or high-energy fracture pattern and recommended various incision types and treatments based on these parameters. The "energy" of the fracture was based on the degree of displacement and comminution. This evidence, however, was anecdotal and not based on any clinical or radiographic outcome criteria.

Russell et al ${ }^{23}$ examined 34 patients over a 2-year period using clinical examination, plain radiographs (normal skull views) and CT scans. They found that in 22 of 24 cases, the CT scans provided additional information (additional fracture information not seen on plain radiographs and degree of displacement) over and above that of plain radiographs and clinical examination. In the remaining 10 cases, $C T$ scans where used because plain radiographs were contraindicated by the patient's clinical condition. This further demonstrated the usefulness of CT scans in the evaluation of facial trauma. 
Finkle et $\mathrm{al}^{24}$ prospectively examined a group of 49 maxillofacial trauma patients' and compared the diagnostic usefuiness of clinical examination, plain films combined with linear tomography, and computed tomography. The suspected fracture lines were recorded based on the observer's examination of the patient and on each of the imaging modalities. In 35 of 49 cases detailed descriptions of the fracture lines were recorded during surgery, which was considered the gold standard. In the remaining 14 patients, surgery was not indicated and CT was considered the gold standard. This study concluded that computed tomography was more accurate than clinical examination, linear tomography and plain radiographs in depicting the location of facial fractures.

Gentry et a ${ }^{25}$, using six cadavers, experimentally produced facial trauma using a $4.5 \mathrm{~kg}$ sledge hammer and a wooden block to fracture the facial bones of cadaveric specimens. These fractures were then evaluated with high resolution CT and confirmed with anatomic evaluation of each specimen. It was concluded that $\mathrm{CT}$ was accurate in the detection and classification of LeFort-type fractures. In addition, it was found that the use of CT enabled the detection of many smaller fractures that were not visualized using plain film and polydirectional tomograms. No quantitative measurements were reported to confirm these findings.

Levy et $\mathrm{al}^{26}$ examined seven cases of zygomatic complex fractures in which both axial and coronal CT images were obtained and reformatted into three-dimensional images. Ten blinded observers examined all CT scans and indicated whether the coronal, axial or 3D images provided the clearest view of the fracture line. There was less information loss when 3D images were reformatted using axial rather than coronal image slices $(p<.025)$. Furthermore, where smaller fracture lines existed, 3D images failed to identify $22.5 \%$ of these additional fracture components. Whether this loss of information was due to the $3 \mathrm{D}$ image processing or whether these fractures were obscured by other structures was not specified. 


\section{COMPUTED TOMOGRAPHY AND MEASURING DISTANCES}

It has been demonstrated that $\mathrm{CT}$ can accurately and reliably demonstrate locations of fractures of the facial skeleton, including the zygomatic complex. Computed tomography, therefore, might be useful in comparing various treatment outcomes that have been described for fractures of the zygomatic complex and could be used to evaluate the restoration of normal zygomatic complex morphology and anatomic position. Some studies have evaluated the accuracy of measurements between osseous structures of the face while others have examined the effect of accurate landmark identification made on CT images. However, there are no investigations to determine if measurements made on CT accurately define the position of the facial bones in relation to the cranial base.

Hemmy and Tessier ${ }^{27}$ compared photos of dry skulls and three-dimensional CT (3D-CT) reformatted images from axial and coronal two-dimensional CT (2D-CT) data. This study assessed the accuracy of reformatted 3D-CT based on the ability of these images to depict vital structures (foramina and sutures) of the cranial base. Scans were obtained with the skull submerged in $0.9 \%$ saline and in air. Axial cuts were $1.5 \mathrm{~mm}$ thick and coronal cuts were $5 \mathrm{~mm}$ thick. Because of the large distance between image slices and the greater slice thickness of the coronal images, a greater number of reformatting errors were noted in the reformatted coronal images compared to reformatted 3D images based on axial scans. These were either errors of exclusion (artifactual holes in the bone or pseudoforamina) or errors of inclusion (artifactual presence of bone when none was actually present). Fewer pseudoforamina were seen in air compared to when the skull was submerged in normal saline. The method used to assess structures and the methods of statistical analysis were not reported. This investigation details quantitative change in 2D-CT compared to 3D-CT but is not applicable to the measurement of distances from axial, coronal or reformatted 3D-CT reconstructed images.

Hahn et $\mathrm{al}^{28}$ collected normative data for intracranial length and width measurements using 215 CT scans of patients who did not have any known intra or extracranial abnormalities. To validate the measurement technique Hahn attempted to quantify the degree of error using a phantom model. Hahn concluded that "The accuracy of the area and distance 
measurements were better than $1 \%$ when measurements were performed on phantoms with comparable dimensions." There was no description of the type of phantom model used, methods and materials, control or assessment of error. If the results are accurate, however, it suggests that $C T$ can accurately measure distances of the cranial vault.

Christiansen et $\mathrm{al}^{29}$ used axial CT images of mandibles imbedded in plastic polymer to study the ability of CT to measure linear distances on dry human mandibles. Sixteen observers repeated the measurements over a period of six months. It was found that the average value of the extracondylar distance (the distance between the most lateral aspect of the right and left condyle) measured on CT images was greater than the corresponding value from the macroscopic measurement. The average difference was $0.8 \pm 0.94 \mathrm{~mm}$, whereas the average difference in intercondylar distance (the distance between the most medial aspect of the right and left condyle) was $0.4 \mathrm{~mm}+0.58 \mathrm{~mm}$. The CT measurement was greater than that of macroscopic measurement for both the right and left transverse condylar dimension (mediallateral width of the condylar head), and the average difference was $0.4 \pm 0.74 \mathrm{~mm}$ for the left and $0.4 \pm 0.79$ for the right. The difference between $\mathrm{CT}$ and macroscopic measurement was not significantly different for any of the measurements.

Matteson et al ${ }^{30}$ compared 3D-CT measurements of bilateral structures on a transversely deformed skull and dry-skull measurements of the same skull. It was found that a mean difference of only $0.28 \%$ existed. Metallic markers were used for accurate reproduction of landmarks and guiding the placement of the cursor for computer-generated measurements. Based on the very low reported error when compared to other studies that did not use markers, this small difference suggests that accurate linear measurement is more dependent on accurate landmark identification than errors introduced by the CT scanner or film production.

$\mathrm{Tjan}^{31}$ examined the accuracy of CT measurements of bilateral structures on dry skulls. Four dry skulls were subjected to direct measurement. Cephalometric, 2D-CT and 3D-CT reformatted images were produced. Measurements were made on the 2D-CT images using specially designed computer software to evaluate distances based on slice thickness and 
location of pixels. This technique was described as the "Pixel Coordinate Method". The 3D-CT images were evaluated on a computer workstation. Tjan concluded that the 3D-CT had less than $10 \%$ error $9 \%$ of the time and the 2D-CT method had less than $10 \%$ error $3 \%$ of the time. The differences between dry skull and 2D-CT images were $4.2 \%$ compared to $10.8 \%$ for $3 \mathrm{D}-\mathrm{CT}$. A $10 \%$ difference (error) in measurements between the tested technique and the gold standard was chosen as the level of accuracy to analyze the data. Based on this, the author stated the two techniques did not differ significantly from the gold standard. Since an average distance between the right and left zygomatic arches can be $100 \mathrm{~mm}$, Tjan's ${ }^{31}$ assumption that implies that $10 \mathrm{~mm}$ of error is not significant. However, a $10 \mathrm{~mm}$ error is likely to be clinically significant in evaluation of the position of the zygomatic arch. The assumption of $10 \%$ error for significance, therefore, may not have any useful clinical application.

$\operatorname{Tjan}^{31}$ also found that 2D-CT had significantly better reproducibility, in making CT measurements of bilateral structures than 3D-CT, despite similar errors of measurement. $\operatorname{Tjan}^{31}$ attributed this to the ability 2D-CT to clearly demonstrate landmarks without adjacent structures obscuring the landmark. The 2D-CT technique was best able to isolate the landmarks of interest. It was concluded that a clearly identifiable landmark will decrease the amount of error and 2D-CT is better than 3D-CT for identification of landmarks.

Waitzmen et $\mathrm{al}^{32}$ used dry skulls with metallic markers to identify landmarks when producing $5 \mathrm{~mm}$ thick 2D-CT axial images. They measured linear distances on dry skull and CT and found the differences ranged from $0.1-3.0 \%$, which were not statistically significant. This study has been widely cited as the basis for the use of CT images to report standard growth trends and to compare the outcomes of different types of facial surgical treatments. $33,34,35,36,37,38$ Since identification of landmarks has been shown to produce substantial variability ${ }^{31}$ it is reasonable to question the clinical application of this study which employed metallic markers. 


\section{THE EFFECT OF GANTRY ANGLE ON MEASURING DISTANCES}

Two sources of measurement error are landmark identification and the error produced by the CT scanner. Since the CT program averages the attenuation of all matter within each pixel of the image (referred to as partial volume averaging) there is an inherent error in depicting the exact position of the bone surface. This will contribute to errors in attempting to arrive at accurate measurements of bone structures on CT image slices. The gantry angle is the angle formed between the infraorbitomeatal line and the gantry of the CT. It establishes the orientation of the image slice to the long axis of the body (see Figure 3). Variations in the orientation of image slices, with respect to the infraorbitomeatal line, are another source of measurement error.

Honda et $\mathrm{al}^{39}$ examined 15 different structures of the skull base on image slices produced at gantry angles of $+40^{\circ}$ to $-70^{\circ}$ to the infraorbitomeatal line using $10 \mathrm{~mm}$ thick axial CT slices (coronal scans were not done). Crista galli, foramen ovale, superior orbital fissure, and anterior clinoid process were clearly visualized $80 \%$ of the time and could be visualized, but not clearly $70 \%$ of the time. The foramen rotundum was clearly seen $18.2 \%$ of the time and not at all $50 \%$ of the time. No statistical anatysis was done. The clinical application of these results is limited by two factors. First, the slice thickness of $10 \mathrm{~mm}$ is much larger than that routinely used for examination of the facial structures. Second, the study was a qualitative assessment of vital structures, rather than a quantitative study of the effect of gantry angle on linear measurements.

Bayley et $\mathrm{a}^{40}$ examined the accuracy of measuring the width of the spinal canal using axial CT scans. The gantry angle was changed from $0^{\circ}$ to $20^{\circ}$. At $0^{\circ}$ and $10^{\circ}$ the canal could be accurately measured, however at $20^{\circ}$ the measurements were no longer accurate. There was no statistical analysis of the data. Also, the spines were disarticulated and stripped of all but their ligamentous and periosteal attachments. This diminishes the effect of surrounding soft tissue structures on the CT image and makes it difficult to orient the spines to the gantry of the CT since there are no reference structures. 
Waitzman et $\mathrm{al}^{32}$ also examined the effect of the gantry angle on the accuracy of measurements, as applied to bilateral facial structures using metallic markers to identify landmarks. He reported that an angle change of greater than $4^{\circ}$ from the infraorbitomeatal line created greater than a $5 \%$ error in the measurements. An error of $5 \%$ was deemed as clinically significant. The measurements of the smallest dimensions were generally those with the largest percent error, however, the amount of error in absolute values was no greater than that for the other measurements overall.

$\mathrm{Tjan}^{31}$ also examined the effect of gantry angle and found that measurements taken at gantry angle $0^{\circ}$ were not significantly different from the gold standard measurements. Measurements made at gantry angle less than $20^{\circ}$ were not significantly different $(p<0.05)$ from measurements made at gantry angle $0^{\circ}$. Gantry angles of $20^{\circ}$ were significantly different $(p<0.05)$ from measurements made at gantry angle $0^{\circ}$. Tjan also concluded that maxillary measurements were more stable than cranial base and mandibular measurements when the gantry angle was changed.

\section{THE EFFECT OF RIGID FIXATION ON CT IMAGES}

Unlike gantry angle, the effect of rigid fixation hardware on the ability to measure distances on 2D-CT has not yet been evaluated. It is known that rigid fixation hardware creates an image artifact in CT images. Artifact in CT images can occur from a number of sources including patient motion and high-attenuation objects. ${ }^{43}$ When a high-attenuation object absorbs the $x$-ray beam a high-density streak artifact obscures adjacent structures in the image slice. Since landmark identification is the chief source of variance in measuring distances on facial $\mathrm{CT}^{31}$, this streak artifact may be a source of a significant error.

Fiala et $\mathrm{ar}^{4 t}$ subjectively quantified the amount of artifact produced by vitallium ( $60 \%$ cobalt, $30 \%$ chromium \& $10 \%$ molydenum) alloy, titanium and stainless steel fixation devices. These devices included micro, mini and mandibular reconstruction systems as well as 28-gauge wire. The metals were placed in a nylon mesh that was submerged in water. The severity of the streak or "starburst" pattern (artifact) was related to fixation device size and material. Titanium caused the least amount of artifact, whereas, stainless steel and vitallium caused greater amounts of artifact. Different thicknesses of titanium plates also 
caused differing amounts of artifact, the thicker the plate, the greater the amount of artifact. However, because the metals were not tested in vivo, the study results may not be directly applicable to the clinical setting.

Sullivan et $\mathrm{a}^{+2}$ completed a similar study using various materials in a beaker filled with gel and arrived at similar conclusions to those of Fiala ${ }^{41}$. In one part of this study, implants comprised of various materials were placed subperiosteally in the orbital floor. Three radiologists, blinded to the material used, quantified the amount of artifact produced by each material. Each radiologist reported significantly more artifact with vitallium implants than with titanium. Vitallium caused more image artifact even when the implant was thinner and had less mass than the titanium implant.

Epply et $\mathrm{a}^{43}$ performed coronal 2D-CT with reformatted 3D-CT images on dry skull models with overlying clay to simulate soft tissue. They also concluded that titanium produced significantly less artifact than stainless steel or vitallium However, the observations were subjective and not quantified.

Barone et $\mathrm{al}^{\text {th }}$ produced axial and reformatted 3D-CT images of 3 adult pig heads after placing mini and micro plating systems composed of vitallium and titanium in the nasoethmoidal region. The amount of artifact for each system was quantified using a computerized measuring tool. The CT images were enhanced, through volume averaging around the artifact streak, in order to diminish the effects of the high attenuation object. No artifact was found with the titanium systems, whereas, the vitallium system increased the amount of artifact. Removal of artifact by image processing increased anatomic detail.

Anastakis et $\mathrm{a}^{45}$ performed a two-part study to assess the effect of different types of rigid fixation on CT images. In the first part, vitallium and titanium devices were secured to a phantom model. The amount of artifact was quantified with the aid of computer software. It was concluded that the severity of image artifact was related to the physical size of the fixation device and its composition. Vitallium devices generated a greater degree of CT artifact than titanium devices of comparable size. In part II of this study, both materials were 
attached to the orbital region of cadaver heads. Three observers examined the bony and soft tissue margins and rated the amount of image degradation on a numerical scale. It was concluded that titanium systems caused no image degradation. In contrast, the vitallium images with plating systems of greater than $2 \mathrm{~mm}$ screw thickness resulted in increased image degradation when viewing the images using the bone algorithm. Smaller metal fixation systems caused image degradation of structures immediately adjacent to the metal fixture when viewing the image in the soft tissue algorithm format.

No investigation has studied the effect rigid fixation hardware has on the ability of CT to measure distances. Tjan ${ }^{31}$ observed that placing stainless steel wire landmarks on dry skulls decreased the amount of error compared to unmarked skulls. Tjan concluded that an artifact-free landmark decreased the amount of observer error by increasing the ease of identifying the landmark.

\section{OBSERVER ERROR AND LINEAR MEASUREMENTS ON CT}

The amount of intra- and inter-observer variability in identification of craniofacial landmarks has been extensively studied. In an investigation by Hahn et al ${ }^{28}$ two radiologists and two CT technicians made linear intracranial measurements on phantom heads. Hahn ${ }^{28}$ reported inter-observer error to be less than $3 \%$, however, this result was reported in the context of a larger study and the materials and methods used to reach this conclusion were not described.

Christiansen et al $^{29}$ performed various measurements on dry mandibles embedded in polymer plastic. Five observer groups examined the CT images including neuroradiologists $(n=3)$, radiology residents $(n=3), C T$ technologists $(n=3)$, dentists $(n=4)$ and paramedical personnel $(n=3)$. The accuracy of intra- and inter-observer variation was then statistically analyzed. No significant difference in observer accuracy was found between groups with different observer experience. The average intra-observer variability was $0.4-0.9 \mathrm{~mm}$ and inter-observer variability $0.5-0.8 \mathrm{~mm}$ when measuring distances of approximately $6-9 \mathrm{~cm}$. Christianson et $\mathrm{al}^{29}$ also found no evidence of a learning effect, since two observers 
examined the CT images on 5 different occasions over 6 months. They used both marked and unmarked landmarks to complete this study.

$\operatorname{Tjan}^{31}$ used 3 observers to perform measurements on two different $\mathrm{CT}$ measurement techniques. There were no significant interobserver differences in the measurements $(p=0.18)$. Tjan ${ }^{31}$ also concluded that the intraobserver variability was similar for all three observers $(p<0.05)$.

\section{THE ASSESSMENT OF FACIAL SYMMETRY}

Several investigations have attempted to quantify the amount of asymmetry in the zygomatic complex region. Direct facial anthropometry is the measurement of the facial structures using landmarks on the soft tissues of the face. ${ }^{46}$ Direct facial anthropometry is usually considered the gold standard in facial measurements and has a variation of approximately $2 \mathrm{~mm}$ in the zygomatic complex region. ${ }^{47}$ Some researchers have defined a means to determine the position of the zygomatic prominence using direct facial anthropometry ${ }^{48}$, which has an intra-observer standard deviation of $2.2 \mathrm{~mm}$ and an interobserver standard deviation of $1.1 \mathrm{~mm}$. Other investigations have examined aesthetically pleasing faces for facial asymmetry and found that an average of $2-3 \mathrm{~mm}$ of asymmetry is normally present in clinically symmetric faces. ${ }^{49}$ To date, no studies have utilized computed tomography for this purpose.

In summary, many methods have been described to treat fractures of the zygomatic complex. Comparison of these treatments, however, is problematic due to the inaccuracies of clinical measurements of the face, especially in an injured patient with swollen soft tissues. Computed tomography offers a more standardized method of measuring the maxillofacial skeleton in order to evaluate various treatment outcomes. The accuracy of CT measurements of some of the facial bones has been assessed but not for the zygomatic complex. Several studies have reported the accuracy of 2D vs. 3D images, variations due to gantry angle, errors in landmark identification and intra- and inter-observer variability. The effect on the accuracy of $\mathrm{CT}$ images due to variation in the sagittal plane (sagittal plane of inclination) of the patient's head within the CT gantry and addition of metal fixation hardware on CT derived measurements has not been studied. 
If $\mathrm{CT}$ could accurately define the position of bones of the facial skeleton in relation to the cranial base it would then be possible to evaluate the degree of facial asymmetry in the zygomatic complex region. This, in turn, would allow an accurate outcome analysis for treatment of zygomatic complex fracture, which is essential for the comparison of various treatment modalities.

The objectives of this study are to:

1. Design and manufacture a dry skull mounting device that will permit CT imaging of multiple dry skulls at different skull orientations submerged in a saline bath.

2. Establish a midline on the skull base and establish various landmarks and linear measurements to locate the zygomatic complex relative to the cranial base.

3. Test the accuracy of landmark identification and linear measurements using CT images compared to dry skull measurements.

4. Test the observer error for both landmark identification and measurements.

5. To evaluate the measurement error introduced by variations of gantry angle and the midsagittal angle of the skull (sagittal plane of inclination).

6. To evaluate the measurement error introduced by the CT machine and by the radiology technologist in creating sequential images.

7. To test the effects of image artifacts from metallic fixation plates on measurement error. 


\section{The Use of Computed Tomography to Define Zygomatic Complex}

\section{Position}

\section{INTRODUCTION}

One of the most common facial fractures is that of the zygomatic complex and arch. $23,4,5$ The zygomatic complex refers to a combination of the zygomatic bone, zygomatic process of maxilla and zygomatic portion of the temporal bone which make up the prominence of the cheek. Studies that have examined esthetic and functional outcomes among patients with differing treatments have lacked objective parameters to compare pre-operative deformity to post-operative results. ${ }^{20.21}$

Although manual and digital anthropometry have been widely described as a means to assess the surface features of the zygomatic complex ${ }^{46,48}$, they are of limited use for patients with swollen soft tissues such as those with facial fractures. There is a need for a more precise and objective method to determine facial symmetry by measuring bony landmarks from a skeletal midline. This would allow one to predict the true position of the injured side based on the position of the non-injured side. In addition, this would allow measurement of treatment outcomes by assessing the degree of skeletal symmetry.

Computed tomography (CT) imaging is the practice standard in assessing facial trauma. It offers an objective means of assessing asymmetries of the zygomatic complex region, however, the reliability, reproducibility, observer variation and other parameters that may cause error in the measurements are uncertain. This investigation tests the use of specific anatomic measurements, as revealed in 2-dimensional CT images, to identify the position of the zygomatic complex relative to the skull base, to test the reliability of these measurements and to determine the factors that may influence their accuracy. 


\section{MATERIALS AND METHODS \\ DIRECT SKULL MEASUREMENTS}

An electronic caliper was modified, by addition of an extendible $\operatorname{arm}^{\dagger}$ (Figure 1) that was accurate to $0.1 \mathrm{~mm}$ throughout its most extended position, to produce linear measurements on the curved surfaces of a skull. This allowed comparison of three-dimensional skull measurements to two-dimensional linear measurements on CT images. A transparent grid with $1 \mathrm{~cm} \times 1 \mathrm{~cm}$ squares was fixed to a square sheet of glass. The mounted, transparent grid was held over the skull base to facilitate the identification of the landmarks as described in Table 1.

\section{CT SCAN MEASUREMENTS}

A plastic container (walls $5.5 \mathrm{~mm}$ thickness) was designed and constructed to mount a dry skull in a $0.9 \%$ saline water bath for the purposes of CT image acquisition (Figure 2). All materials used were non-metallic to avoid artifacts in the CT images. A skull mount with a ball and socket configuration permitted differing orientations of the skull relative to the xray beam. Changes in the position of the skull that allowed for alterations in the orientation of the image slice in the axial and coronal tissue planes will be referred to as the plane of gantry (Figure 3). The entire tank was mounted on a base with a ball and socket configuration at the centre of rotation to allow movement of the tank and skull in a horizontal plane perpendicular to the gantry. Normally the sagittal plane of the skull is perpendicular to the xray beam or gantry. This device permitted changes in the horizontal plane, hence, the sagittal plane of the skull relative to the scanning xray beams. This will be referred to as the sagittal plane of inclination (Figure 4). Markings were made at $5^{0}$ increments on the base to allow accurate changes in the sagittal plane of inclination. To provide a variety of skull types four dry skulls were chosen, at random, as the test skulls with a variation of approximately $10 \mathrm{~mm}$ in the measured distances. Each skull was free of any obvious deformities of the zygomatic complex region.

\footnotetext{
Mitutoyo Digimatic Ruler Code No. 500-341, Model CD-ISDP, Serial No. 0008494

+ The mount was built by the medical engineering department at The Hospital for Sick Children, Toronto, Canada
} 


\section{ACQUISITION OF CT IMAGES}

Images were acquired on a GE $9800 \mathrm{HLA}$ scanner ${ }^{\ddagger}$. One technologist completed all positioning and scans to maintain uniformity. The orientation of the skull was completed using laser lines and "scout scans" by the same technologist in the same fashion that a patient would be positioned. Scans were oriented parallel to Frankfort horizontal for axial scans and perpendicular to it for coronal scans ${ }^{\S}$. The scans were performed with consecutive $3.0 \mathrm{~mm}$ intervals extending from the superior aspect of the orbit to the palatal vault axially and from the anterior nasal spine to the posterior aspect of the foramen magnum coronally.

\section{SELECTION AND MEASUREMENTS OF CT IMAGES}

The axial image slice where the zygomatic arches appeared to be thickest was selected by visual exam of consecutive images for axial measurements, which was analogous to the orientation of the direct skull measurements. When one axial image failed to demonstrate ideal images of both zygomatic arches two axial images were used, one for the right and one for the left. The coronal image slice selected contained the lateral orbital rims in their entirety as well as the zygomatic arches. When one coronal image was not ideal two coronal images were used, one for each of the right and left sides.

Imaging data were collected and transferred to a computer workstation" and displayed in bone algorithm for measurements using Advantage Review Remote (ARR) ${ }^{\otimes}$ software. $^{\dagger t}$ A transparent $1 \mathrm{~cm} \times 1 \mathrm{~cm}$ grid was used as an overlay on the computer screen to facilitate the identification of the measurement landmarks. Coronal and axial midlines were defined and three landmarks identified to determine the posterior zygomatic complex width

: General Electric 9800 HLA CT Scanner I.D. 416864 CT

s $512 \times 512$ matrix, $170 \mathrm{~mA}, \mathrm{kV} 120$, scan time $=2.0 \mathrm{~s}$, display field of view $=17$, scan field of view $=34.5$ (coronals), 25 (axials)

- Transferred via coaxial cable and PCM-CIA card to laptop then station computer. PNG (Portable Network Graphics) file format for networking to prevent any data loss with transfer.

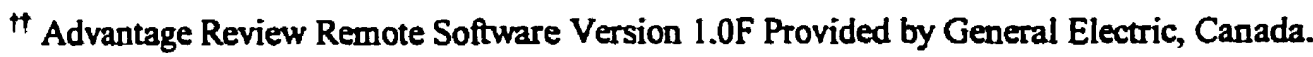


(measurement 1), anterior zygomatic complex width (measurement 2), zygomatic complex projection (measurement 3) and zygomatic complex height (measurement 4). All landmarks, midlines, reference lines and measurements are listed in Table 1 and depicted in Figures 5 and 6.

\section{STUDY SIZE}

A pilot study was performed to determine the number of observers and observations required to achieve an alpha of 0.05 and a power of greater than $80 \%$. Two measurements (numbers 1 and 4) perceived to be the easiest and most difficult to reproduce on the dry skull were measured 10 times on the same day by three observers on the CT image and dry skull. Power and size estimates calculated that to achieve an alpha $=0.05$ and a power greater than $80 \% ; 5$ observers would be required to repeat the observations 3 times.

\section{SKULL MEASUREMENTS}

The four measurements, already described, were performed directly on each of the right and left sides of four skulls. Each landmark was identified using a stick-on paper dot, which was removed between repetitions. Each measurement was repeated, in succession, three times by five observers using the digital caliper. All observers prevented from viewing each measurement by covering the display screen of the gaugecaliper. All measurements were immediately recorded by a second person to an accuracy of $0.1 \mathrm{~mm}$.

Before making the CT and skull measurements the five observers participated in calibration exercises to ensure understanding and agreement with the identification of landmarks. With the aid of the grid, all landmarks were identified and marked on the computer screen with the cursor. The measurements were made and repeated 3 times by each of the 5 observers using the measuring tools with the ARR software, which allowed measurements to $1 \mathrm{~mm}$ accuracy. Each measurement was recorded to $1 \mathrm{~mm}$ accuracy by a second observer. The observers were prevented from viewing the digital value of the measurement. 


\section{CT SCANNER AND TECHNOLOGIST ERRORS}

The axial scans were completed after positioning the skull and orienting the gantry angleand inclination at $0^{\circ}$. The CT technologist then removed and repositioned the skull as closely as possible to the same position to determine the error associated with skull positioning by the technologist. Finally, a series of scans were repeated without moving the skull to determine the error associated with the CT scanner. This procedure was repeated with the coronal images.

\section{EFFECT OF GANTRY ANGLE AND SKULL INCLINATION}

Using the procedure described above, the skull was scanned with a gantry angle of $5^{\circ}, 10^{\circ}$, $15^{\circ}$ and $20^{\circ}$ to the Frankfort plane for axial image slices and at $85^{\circ}, 80^{\circ}, 75^{\circ}$ and $70^{\circ}$ for coronal image slices. This provided image slices of various angles in the axial and coronal planes. The skull was again scanned using the protocol described above such that the sagittal plane of inclination was at $85^{\circ}, 80^{\circ}, 75^{\circ}$, and $70^{\circ}$ to the gantry of the CT scanner. This provided image slices in various sagittal inclinations.

\section{EFFECT OF RIGID FIXATION HARDWARE}

A $1.3 \mathrm{~mm}$ straight 6 -hole Synthes ${ }^{\oplus}$ titanium rigid fixation plate was secured to the zygomatic arch with six $1.3 \mathrm{~mm}$ diameter, $5 \mathrm{~mm}$ long self-tapping screws. The skull was scanned using the protocol described above with a $0^{\circ}$ gantry angle and $0^{\circ}$ inclination. This provided images that had been altered by metal image artifacts.

\section{STATISTICAL ANALYSIS}

Data were then analyzed using a mixed effect analysis of variance model. The model was estimated using SAS version 6.12 software ${ }^{\#}$. Side of skull and method were treated as fixed effects, while observer and skull were treated as random effects. This allows one to assess the effect of method (CT vs direct) and side (left vs right) on measurement, after adjusting for variation between skulls and variation between observers.

\footnotetext{
\#SAS Institute Inc., SAS/STAT Software: Changes and enhancements through Release 6.12, Cary, N.C.: SAS Institute Inc., 1997. 1167pp.
} 
The discrepancy between skull and CT scan measurements on the left side of the face was compared with that of the right side. CT symmetry was defined as the difference between the left and right side CT measurements. Skull symmetry was defined as the difference between the left and right side skull measurements. The model also facilitated testing whether these two symmetry values were different from one another.

A mixed effect analysis of variance was performed where side of face and instrument errors were treated as fixed effects and observer was treated as a random effect. A series of contrasts were performed to compare each level of error (scanner error, technologist error, gantry angle, skull inclination, and rigid fixation) to the reference level.

A clinically significant difference of $2.5 \mathrm{~mm}$ between dry skull and CT scan assessment was chosen because this is the mean amount of asymmetry that must be present in the zygomatic complex region before it is visibly noticeable. ${ }^{49}$ A clinically significant difference of $1 \mathrm{~mm}$ between levels of error due to the different observers, CT scanner, technologist, gantry angle changes, changes in skull inclination and addition of rigid fixation was chosen because measurements of less than $1 \mathrm{~mm}$ are inaccurate.

\section{RESULTS}

\section{INTEROBSERVER VARIATION}

Using the mixed effect anatysis of variance model the interobserver variation was estimated. This model produces an estimate of the variance between observers after accounting for the variance due to method (measurements of CT scan or direct skull measurements), side (left or right) and skull (1-4). The estimate of interobserver variation for measurements $1,2,3$ and 4 was $0.02 \pm 0.03 \mathrm{~mm}^{2}, 0.5 \pm 0.4 \mathrm{~mm}^{2}, 3.5 \pm 2.6 \mathrm{~mm}^{2}$ and $0.4 \pm 0.3 \mathrm{~mm}^{2}$ respectively. None was statistically significant $(p>0.05)$. Measurement 3 was clinically significant as it was greater than $1 \mathrm{~mm}$. 


\section{ACCURACY OF CT VS DRY SKULL MEASUREMENTS}

Contrasts comparing the direct caliper measurements on the dry skull with their counterparts in the CT images, for each side of face, revealed clinical and statistically significant differences for all measurements except Measurement 1 (Table 2). Interestingly, there were significant differences between the left and right sides for each measurement.

\section{ACCURACY OF CT VS DRY SKULL IN ASSESSING SYMMETRY}

Analysis of symmetry revealed minimal differences between $\mathrm{CT}$ and skull measurements. In the assessment of symmetry, the mean differences between $\mathrm{CT}$ and dry skull estimates were $1.2 \pm 0.3 \mathrm{~mm}$ for measurement $1,0.4 \pm 0.4 \mathrm{~mm}$ for measurement $2,1.4 \pm 0.7 \mathrm{~mm}$ for measurement 3 and $1.1 \pm 0.5 \mathrm{~mm}$ for measurement 4 (Table 3). All measurements $95 \%$ confidence intervals ( $\mathrm{CI}$; mean $+2(\mathrm{SD})$ ) were below $2.5 \mathrm{~mm}$ except for measurement 3 . Measurement 1 showed a statistically significant difference between CT and skull $(P<0.0001)$. All other measurements showed no significant differences $(p>0.05)$.

\section{EFFECT OF INSTRUMENT ERROR}

Repeat CT scans without repositioning the skull had no significant effect on repeated measurements when compared to the standard scan (Table 4). The maximal effect was in measurement 4 which had a difference of $0.3 \pm 0.3 \mathrm{~mm}$.

\section{EFFECT OF TECHNOLOGIST ERROR}

Measurements derived from repeated CT scans with the skull removed from the scanner and replaced as close to the original position by the $\mathrm{CT}$ technologist showed mean differences of less than $1 \mathrm{~mm}$ (Table 5) for all measurements. The effect of measurement error introduced by repositioning the skull was not statistically significant except for measurement 4 which had a mean difference of $0.9 \pm 0.3 \mathrm{~mm}(p=0.006)$.

\section{EFFECT OF VARIATIONS IN THE PLANE OF GANTRY}

The amount of error introduced by variation in gantry angle was dependent on the particular measurement. A gantry angle of $5^{\circ}$ had no effect on any measurement. For a gantry angle of $10^{\circ}$, measurements 2,3 and 4 were statistically significantly different from the $0^{\circ}$ measurements. Measurements 2 and 4 had less than $1 \mathrm{~mm}$ of difference while measurement 
3 had greater than $3 \mathrm{~mm}$ of difference. For gantry angles of $15^{\circ}$ and $20^{\circ}$, measurements 1 and 4 were not significantly different from the standard, while measurements 2 and 3 were statistically different and greater than $1 \mathrm{~mm}$. Repeat CT scans with changes of the gantry angle of the CT scanner in $5^{\circ}$ increments revealed mean differences listed in Table 6.

\section{EFFECT OF VARIATIONS IN THE SAGITTAL PLANE OF INCLINATION}

For skull inclinations of $15^{\circ}$ and $20^{\circ}$ landmarks were out of the scan field (the 2-dimensional area of the scan). It was, therefore, impossible to make measurements at these inclinations as the landmarks could not be seen. Repeat CT scans with changes of skull inclination in $5^{0}$ increments revealed mean differences listed in Table 7 . Only measurement 3 had differences greater than $1 \mathrm{~mm}$ at $5^{\circ}$ and $10^{\circ}$.

\section{EFFECT OF RIGID FIXATION}

The mean differences in measurements from the standard scan for repeated CT scans with the addition of a rigid fixation metal plate to the zygomatic arch are listed in Table 8. There were no significant differences noted with the addition of a $1.3 \mathrm{~mm}$ titanium mini-plate for any of the measurements.

\section{DISCUSSION}

The hypothesis of this experiment was that the location of the zygomatic complex relative to the cranial base could be precisely established using $\mathrm{CT}$ images. The ability of CT to measure bilateral distances on the skull has been investigated by others ${ }^{30,32}$. These studies suggest that when markers are used to identify landmarks, the total error in measurements is not significant compared to the distances being measured (i.e., less than $1 \%$ of the measured distance). Markers allow an easy method of reproducibly identifying landmarks, which in turn decreases intra and inter-observer variation. Use of markers allows determination of error associated with the CT scanner but is not applicable to the clinical setting since markers cannot be used on live patients. 
Bilateral measurements on other structures of the skull (cranial vault and mandibular condyles) without the use of markers have been done in other studies ${ }^{28.29}$. These investigators found less than $1 \%$ measurement error but did not study the effect of confounding variables such as gantry angle, inclination and other sources of error.

$\mathrm{Tjan}^{31}$ examined the accuracy of CT scans to measure distances on dry skulls. The difference between dry skull and 2-dimensional CT images was $4.2 \%$ compared to $10.8 \%$ for 3-dimensional CT. Tjan also found that 2-dimensional CT had significantly better reproducibility compared to 3-dimensional CT, despite similar accuracy. Tjan attributed this to the ability of 2-dimensional CT to clearly demonstrate landmarks without encroachment from adjacent structures. The presence of markers on the landmarks had a significant positive effect on the amount of error, which confirms that a clearly identifiable landmark will decrease the amount of error.

The results of the present study indicate that CT measurements for unilateral structures do not match their direct skull counterparts with the exception of measurement 1 . The dry skull measurements were generally less than their $\mathrm{CT}$ counterparts for measurements 1, 2 and 3. For measurement 4 the dry skull measurements were generally greater than the CT measurements. This is likely due to the difference in the ability of the observers to identify the same landmarks on $\mathrm{CT}$ and on the dry skulls for both the measurement and midline measurements. When relative measurements were used to evaluate the amount of symmetry (difference in the left to right side measurements on direct skull and CT measurements) there were no significant differences except for measurement 1 . Since the interobserver variation is low it indicates that the observers were able to consistently identify landmarks. Even though the landmarks were not the same on the CT as on dry skull it appears both methods provide a similar assessment of asymmetry.

Statistical significance in measuring the position of osseous structures, however, does not equate to clinical significance. This is partially due to other parameters such as the soft tissue components of the face. Direct facial anthropometry, usually considered the gold standard in facial measurements has a variation of approximately $2 \mathrm{~mm}$ within 
measurements of the zygomatic complex region ${ }^{47}$ Furthermore, an average of $2-3 \mathrm{~mm}$ of asymmetry is normally present in clinically symmetric faces. ${ }^{49}$ The differences in the measurement of symmetry between direct measurement and CT for measurements 1 through 4 were $1.2 \mathrm{~mm}(95 \% \mathrm{CI} 0.58-1.8 \mathrm{~mm}), 0.44 \mathrm{~mm}(95 \% \mathrm{Cl}-0.38-1.3 \mathrm{~mm}), 1.4 \mathrm{~mm}(95 \%$ $\mathrm{CI}-0.05-2.9 \mathrm{~mm})$ and $1.1 \mathrm{~mm}(0.05-2.2 \mathrm{~mm})$ respectively. Because the measured differences $(95 \% \mathrm{Cl})$ are less than $2.5 \mathrm{~mm}$, with the exception of measurement 3, measurements 1, 2 and 4 all have the same degree of variation that would normally be present in direct facial anthropometry. These distances could be used to determine the degree of facial symmetry in the zygomatic complex region. The likely reason measurement 3 was less accurate is because it is derived from the landmarks of measurements 1 and 2 and represents the summation of their errors. Ideally, a set of landmarks that define zygomatic projection, and are independent of the other measurements should be used. Possibly using the same anterior landmarks but using the external auditory meatus or a base of skull for the posterior landmark could be tested.

Although the above data show that CT measurements can determine facial symmetry other factors can influence accuracy of the measurements. One millimeter was chosen as a significant difference when assessing for the effect of CT scanner error, technologist error, gantry angle changes, changes in skull inclination and addition of rigid fixation hardware. Since the CT program averages the attenuation of all matter within each pixel of the image (referred to as partial volume averaging) there is an inherent error in depicting the exact position of the bone surface. This will contribute to enrors in attempting to arrive at accurate measurements of bone structures. However, in this experiment partial volume averaging did not have an influence on repeated direct measurements as demonstrated by the low amount of CT scanner error. Similarly, the CT technologist did not introduce any clinically significant differences when placing the test subject in the CT scanner.

Others have studied the effects of gantry angle on measurements made with $\mathrm{CT}$ images. Both Bayley et $\mathrm{a}^{40}$ and $\mathrm{Tjan}^{31}$ concluded that gantry angle changes of less than $20^{\circ}$ have no effect on measurements. Waitzman et $\mathrm{al}^{32}$, however, reported that gantry angles of greater than $4^{\circ}$ created measurement error and that measurements of the smallest dimensions were 
generally those with the largest percent difference. The greater effect of gantry angle found in Waitzman's results is likely due to the use of metallic markers. Because different observers created less error in identifying landmarks (due to the use of metallic markers) the relative effect of gantry angle appears greater.

The data presented in this investigation tend to support that of $\mathrm{Tjan}^{31}$, in that the sensitivity of the measurements to gantry angle is dependent on the particular measurement. For measurement 1 , gantry angle changes of up to $20^{\circ}$ seem to have no effect. This measurement was the longest, so a similar percentage error would have less overall effect on the error as described by Waitzman et al ${ }^{32}$. Measurement 1 was also the easiest to identify which would also decrease the amount of enror. Measurement 2 was repeatable at $5^{0}$, but was significantly different at $10^{\circ}, 15^{\circ}$ and $20^{\circ}$. At greater gantry angles the landmarks used to create measurement 2 had to be identified on different scans, which likely increased the error. It may be that 3-dimensional reconstruction would decrease the amount of etror in this measurement. Measurement 3, which has already been shown to be unreliable was very sensitive to gantry angle changes greater than $5^{0}$ likely because it is dependent on the landmarks of both measurement 1 and 2. It is, therefore, a summation of their respective errors. Measurement 4 was not sensitive to gantry angle changes, except at the $10^{\circ}$ level. It is unclear why $10^{\circ}$ would result in a statistically significant difference for measurement 4 , however, the difference was not clinically significant. It is possible this difference is due to chance alone.

Sagittal inclinations of $15^{\circ}$ and $20^{\circ}$ took the skull far enough out of the scan field that the identification of landmarks became impossible. No attempt was made to alter the scan field to capture the arch since this would not be done clinically since the technologist would reorient the patient's skull and repeat the CT scan. Although there was a statistically significant error for measurements 1,2 and 4 at inclinations of $5^{\circ}$ and $10^{\circ}$, these were not clinically significant (i.e., less than $1 \mathrm{~mm}$ ). The enror for measurement 3 was clinically significant (greater than $1 \mathrm{~mm}$ ) at 5 and 10 degrees of change. This may be due to difficulties with landmark identification. This is substantiated by the fact that there was significant error with repeated measurements without alterations in gantry or skull angles. 
Although several investigators ${ }^{44,45}$ have quantified the degree of artifact associated with different types of rigid internal fixation, none has examined its effect on CT derived measurements. It was expected that image artifact from the high attenuation of metallic fixation plates would reduce the accuracy of landmark identification thereby increasing measurement error. Surprisingly, the results presented in this investigation indicate that there was no significant effect on measurement error. The lack of effect is likely due to the titanium metal and $1.3 \mathrm{~mm}$ plate size. This is the most common plate used to fixate ZMFC fractures. It does not, however, create significant amounts of artifact and image degredation. If a greater thickness of plate was used $(2.0$ or $2.3 \mathrm{~mm})$ or a vitallium plate a greater effect may have been found. This validates the use of $\mathrm{CT}$ to assess treatment outcome, even when low-profile titanium fixation hardware is included in the images.

\section{CONCLUSIONS}

This investigation has resulted in the establishment of a midline on the base of the skull, reference lines and landmarks that can be used on two-dimensional CT images to assess the position of the zygomatic complex. It was found that the posterior and anterior zygomatic complex width and zygomatic complex height (measurements I, 2 and 4) have a clinical application to determine, quantitatively, the degree of facial symmetry. These measurements are not sensitive to error introduced by the CT technologist, CT scanner, low levels of gantry angle changes and up to $10^{\circ}$ of skull inclination. The addition of a $1.3 \mathrm{~mm}$ titanium rigid fixation hardware plate does not appear to change the accuracy of the measurements. With the knowledge that errors introduced during clinical use are unlikely to have a significant effect, the measurements, described in this investigation, can be used to assess zygomatic complex fractures. This investigation could be extended by using independent landmarks for measurement 3 , using additional types of rigid fixation to create different artifact and having the technologist replace the skulls more than one in the CT scanner. Future investigations should include, a retrospective study should be completed comparing pre- to post-operative CT studies of patients who have undergone zygomatic complex repair to determine if the measurements employed in the study are significantly different after 
treatment. This will help determine the sensitivity of the measurements described in actual treatments. If the measurements described prove to be sufficiently sensitive, CT images can be used to quantitatively compare the ability of different treatments to restore facial symmetry. 
Table 1 - Description of Reference Lines, Landmarks and Measurements

\begin{tabular}{|l|l|}
\hline Reference Line or Measurement & Anatomic Description \\
\hline Axial Midline (Figure 5) & $\begin{array}{l}\text { Axial measurements were made from a line perpendicular } \\
\text { to an imaginary sagittal line drawn posteriorly from vertical } \\
\text { plate of ethmoid anteriorly to the midline of the clivus on } \\
\text { the skull base or the midline of the foramen magnum } \\
\text { (whichever was most easily identified). }\end{array}$ \\
\hline $\begin{array}{l}\text { Measurement 1 (Figu re 5) } \\
\text { (Posterior Zygomatic Complex Width) }\end{array}$ & $\begin{array}{l}\text { The grid was aligned to the aria! midline. Measurement } \\
\text { was the measurement of the distance from the midline to } \\
\text { the most lateral aspect of the curve of the zygomatic arch }\end{array}$ \\
\hline $\begin{array}{l}\text { Measurement 2 (Figure 5) } \\
\text { Anterior Zygomatic Complex Width) }\end{array}$ & $\begin{array}{l}\text { The grid was aligned to the axial midline and a point was } \\
\text { marked on the most anterolateral aspect of the zygomatic } \\
\text { complex. This point was established by the intersection of a } \\
\text { line perpendicular to the axial midline extending laterally } \\
\text { and through the most anterior portion of the zygomatic arch } \\
\text { and a line parallel to the axial midline extending anterior } \\
\text { from the most lateral aspect of the zygomatic arch. A } \\
\text { bisecting line from the intersection of these two lines was } \\
\text { drawn to the outer surface of the zygomatic arch. } \\
\text { Measurement 2 was the measurement of the distance from } \\
\text { the midline to this point }\end{array}$ \\
\hline $\begin{array}{l}\text { Measurement 3 (Figure 5) } \\
\text { (Zygomatic Complex Projection) }\end{array}$ & $\begin{array}{l}\text { The distance between the two points established on the } \\
\text { zygomatic arch for measurements I and 2 is measurement } \\
\text { 3. }\end{array}$ \\
\hline $\begin{array}{l}\text { Coronal midline and Reference } \\
\text { Line (Figure 6) }\end{array}$ & $\begin{array}{l}\text { The grid was aligned to a midline through the most } \\
\text { superior aspect of the suture joining the nasal bones and the } \\
\text { midline crest of the maxilla. A second line, perpendicular } \\
\text { to the first, was aligned on the grid through the most } \\
\text { superior aspect of the superior orbital rims. This was } \\
\text { referred to as the horizontal reference line. }\end{array}$ \\
\hline $\begin{array}{l}\text { Using the grid the most lateral aspect of the curved surface } \\
\text { of the zygomatic complex was identified. Measurement 4 } \\
\text { was the measurement of the distance between the } \\
\text { horizontal reference line and the point of the zygomatic } \\
\text { complex. }\end{array}$ \\
\hline Complex Height)
\end{tabular}


Table 2 - Mean differences between dry skull and CT measurement for the left and right side of skull ( $\mathrm{mm}$; Mean \pm SD)

\begin{tabular}{l|ll} 
& Left $^{*}$ & Right $^{*}$ \\
\hline Measurement 1 & $0.2 \pm 0.2$ & $0.9 \pm 0.2^{*}$ \\
Measurement 2 & $2.9 \pm 0.3^{*}$ & $2.4 \pm 0.3^{*}$ \\
Measurement 3 & $4.9 \pm 0.5^{\star}$ & $6.3 \pm 0.5^{*}$ \\
Measurement 4 & $4.0 \pm 0.4^{*}$ & $2.9 \pm 0.4^{\star}$ \\
*indicates statistical significance & $<0.05$
\end{tabular}

${ }^{*} a$ positive number indicates the $C T$ measurement was greater than the dry skull measurement 
Table 3 - Mean differences in the assessment of symmetry between dry skull and CT measurements (mm; MeantSD)

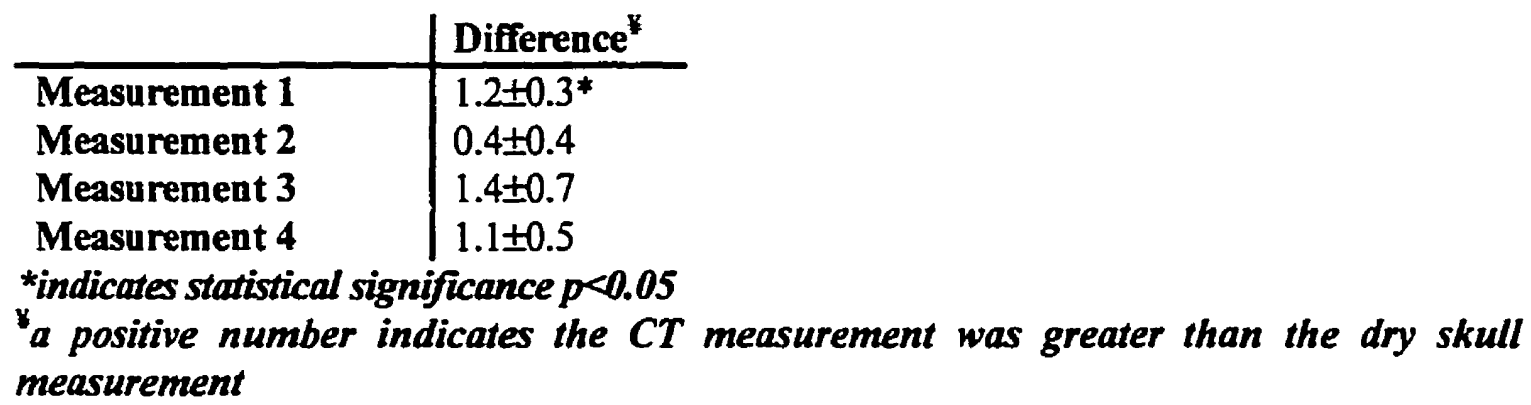


Table 4 - Mean differences in measurements after repeating scan in same position (mm; Mean \pm SD)

\begin{tabular}{l|c} 
& Difference \\
\hline Measurement 1 & $-0.1 \pm 0.2$ \\
Measurement 2 & $0 \pm 0.4$ \\
Measurement 3 & $0 \pm 0.5$ \\
Measurement 4 & $0.3 \pm 0.3$
\end{tabular}

*indicates statistical significance $p<0.05$

a positive number indicates the CT measurement was greater than the dry skull measurement 
Table 5 - Mean differences in measurements after repositioning by the $\mathrm{CT}$ technologist (mm; Mean \pm SD)




Table 6 - Mean differences in measurements with variations in gantry angle $(\mathrm{mm}$; Mean \pm SD)

\begin{tabular}{l|cclc} 
& Gantry 5* & Gantry 10 & Gantry 15* & Gantry 20 \\
\hline Measurement 1 & $-0.1 \pm 0.2$ & $-0.1 \pm 0.2$ & $-0.3 \pm 0.2$ & $-0.5 \pm 0.2$ \\
Measurement 2 & $0.5 \pm 0.4$ & $-0.7 \pm 0.4^{*}$ & $-1.7 \pm 0.4^{*}$ & $-1.9 \pm 0.4^{*}$ \\
Measurement 3 & $0.6 \pm 0.5$ & $3.4 \pm 0.5^{*}$ & $4.4 \pm 0.5^{*}$ & $4.6 \pm 0.5^{*}$ \\
Measurement 4 & $0.0 \pm 0.3$ & $0.7 \pm 0.3^{*}$ & $0.3 \pm 0.3$ & $-0.1 \pm 0.3$
\end{tabular}

${ }^{*}$ indicates statistical significance $p<0.05$

a positive number indicates the CT measurement was greater than the dry skull measurement 
Table 7 - Mean differences in measurements with variations in skull inclinations (mm; MeantSD)

\begin{tabular}{l|ll} 
& Inclination $5^{*}$ & Inclination $10^{*}$ \\
\hline Measurement 1 & $-0.3 \pm 0.2$ & $-0.2 \pm 0.2$ \\
Measurement 2 & $-0.8 \pm 0.4^{*}$ & $-0.4 \pm 0.4$ \\
Measurement 3 & $2.6 \pm 0.5^{*}$ & $1.5 \pm 0.5^{*}$ \\
Measurement 4 & $-0.2 \pm 0.3$ & $-0.3 \pm 0.3$
\end{tabular}

*indicates statistical significance $p<0.05$

a positive number indicates the CT measurement was greater than the dry skull measurement 
Table 8 - Mean differences in measurements with addition of a rigid fixation plate (mm; MeantSD)

\begin{tabular}{l|l} 
& Difference \\
\hline Measurement 1 & $-0.1 \pm 0.2$ \\
Measurement2 & $0.1 \pm 0.4$ \\
Measurement 3 & $0.1 \pm 0.5$ \\
Measurement 4 & $0.1 \pm 0.3$
\end{tabular}

*indicates statistical significance p<0.05

*a positive number indicates the CT measurement was greater than the dry skull measurement 
Figure 1 - Extendable Ruler

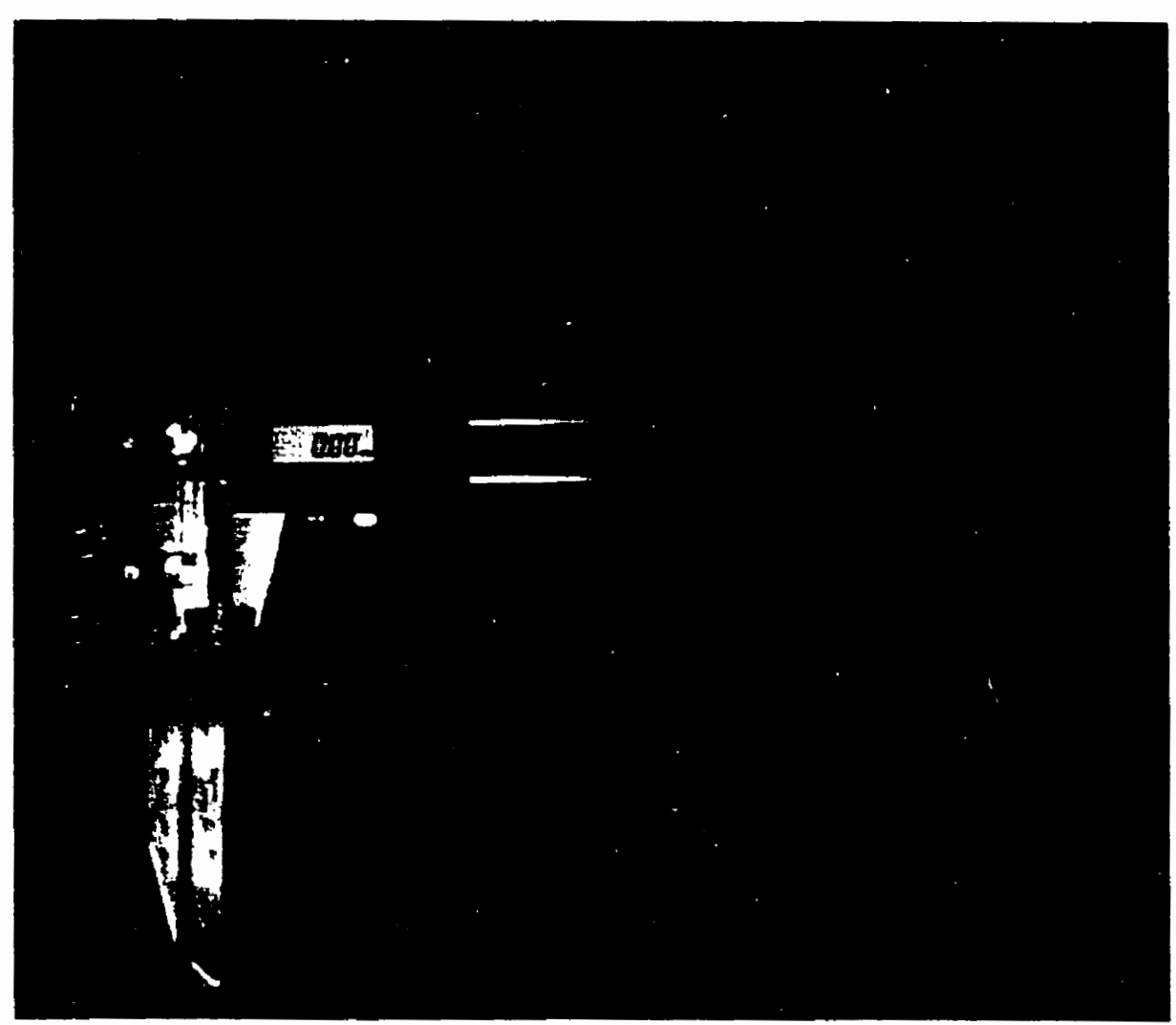


Figure 2 - Plastic Container and Mount for Skull in CT Scanner

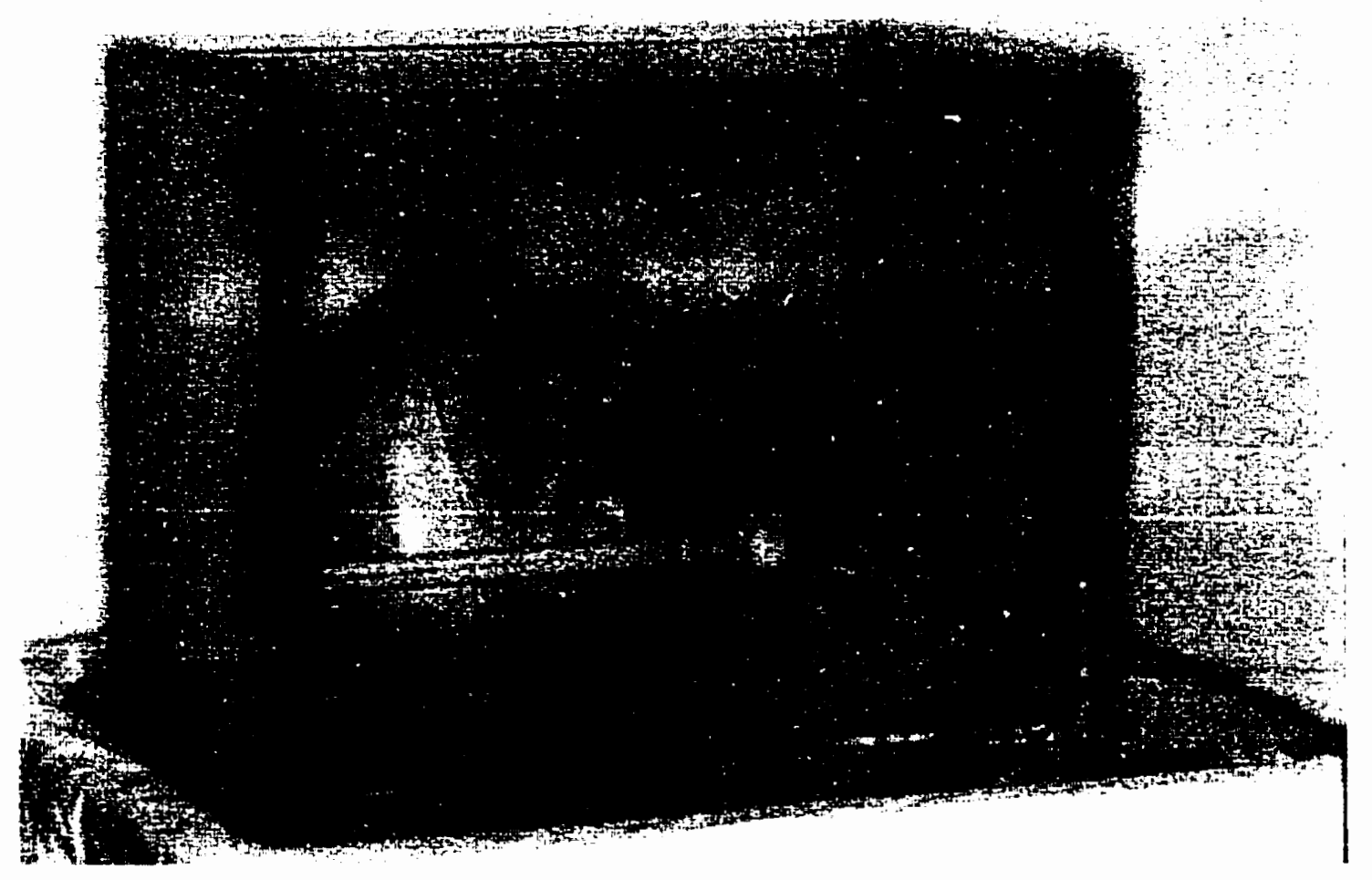


Figure 3 - Plane of Gantry Angle

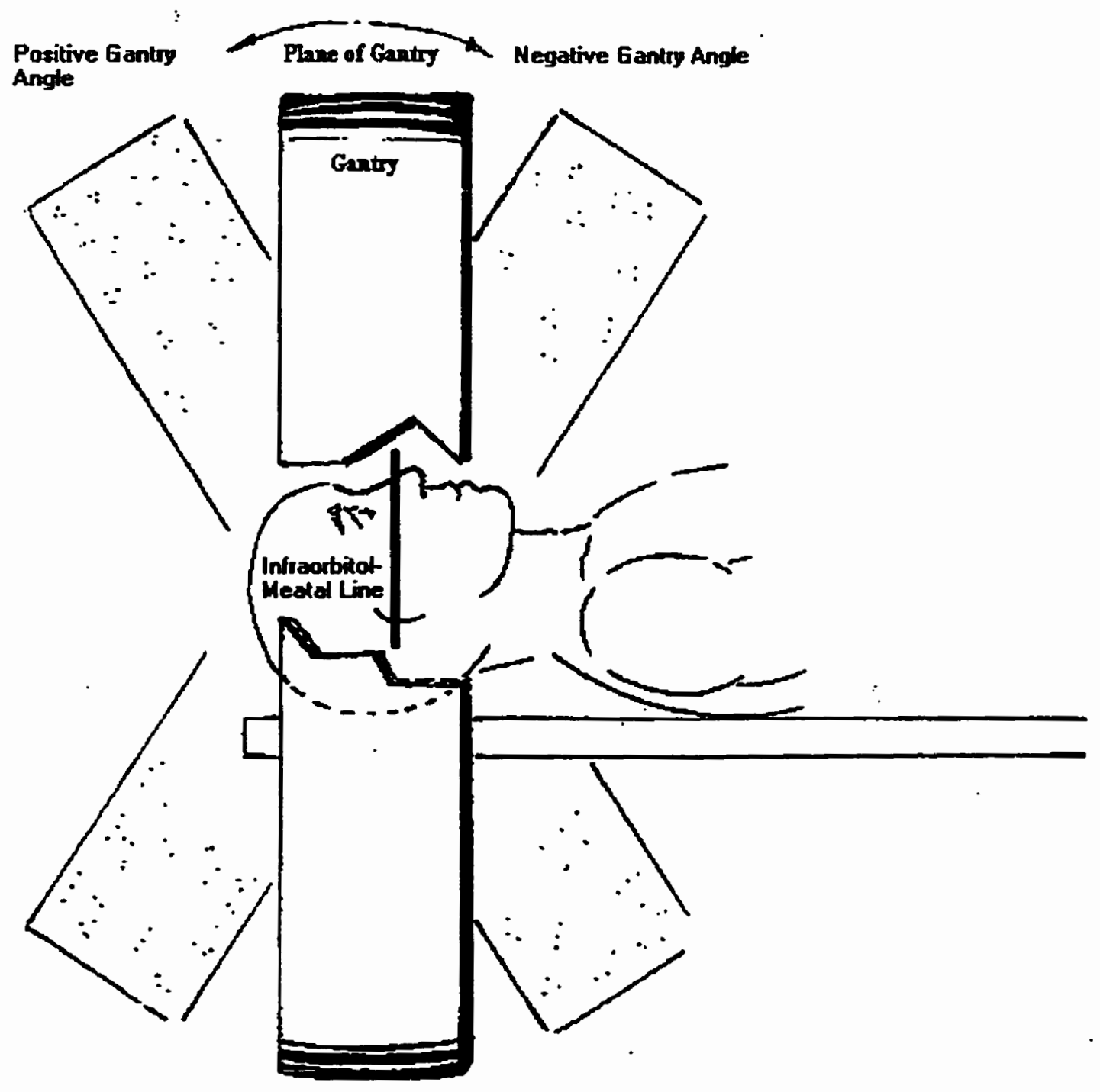


Figure 4 - Sagittal Plane of Inclination




Figure 5 - Axial CT Image with Landmarks, Reference Lines and Measurements

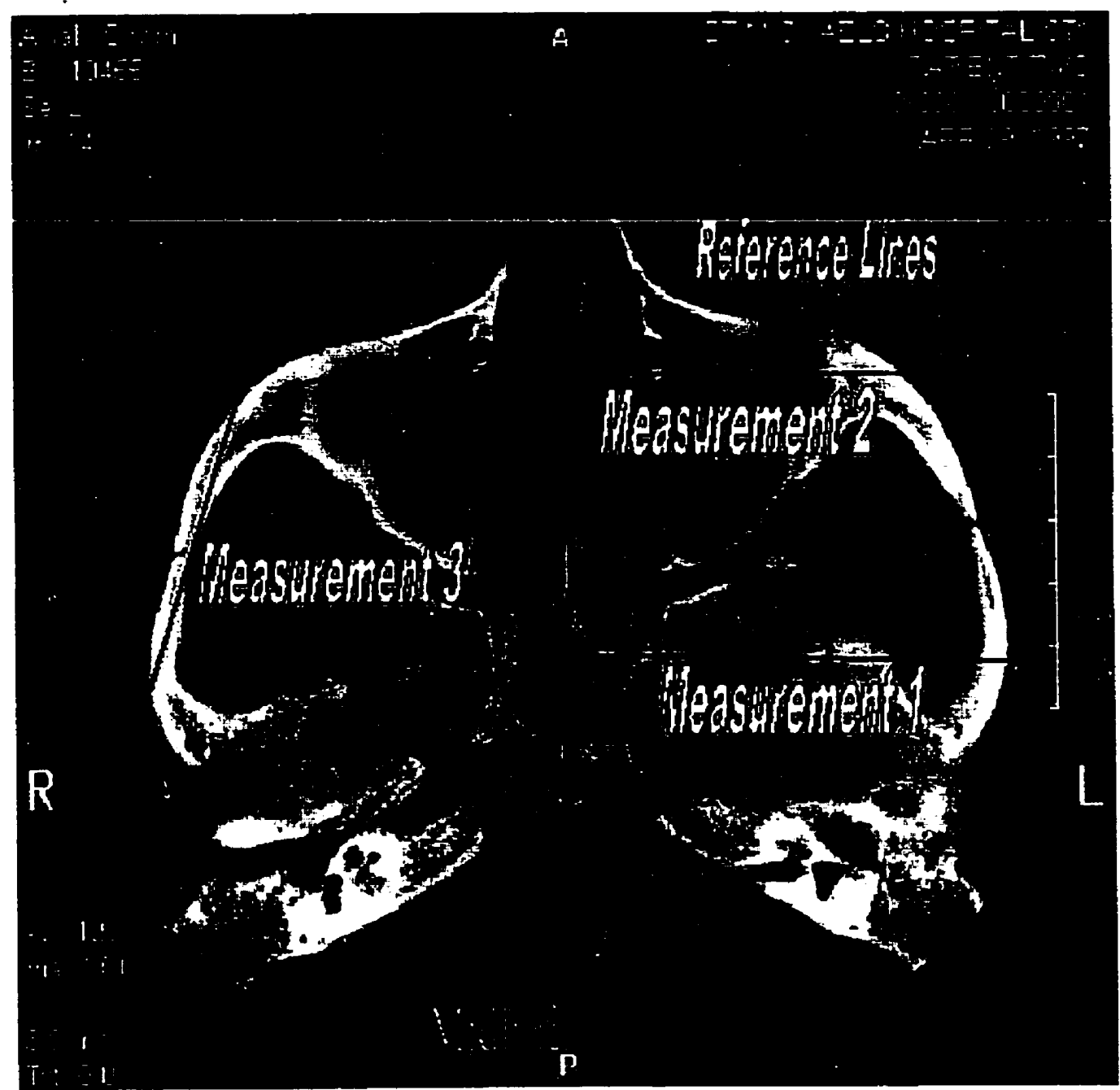


Figure 6 -Coronal CT Image with Landmarks, Reference Lines and Measurements

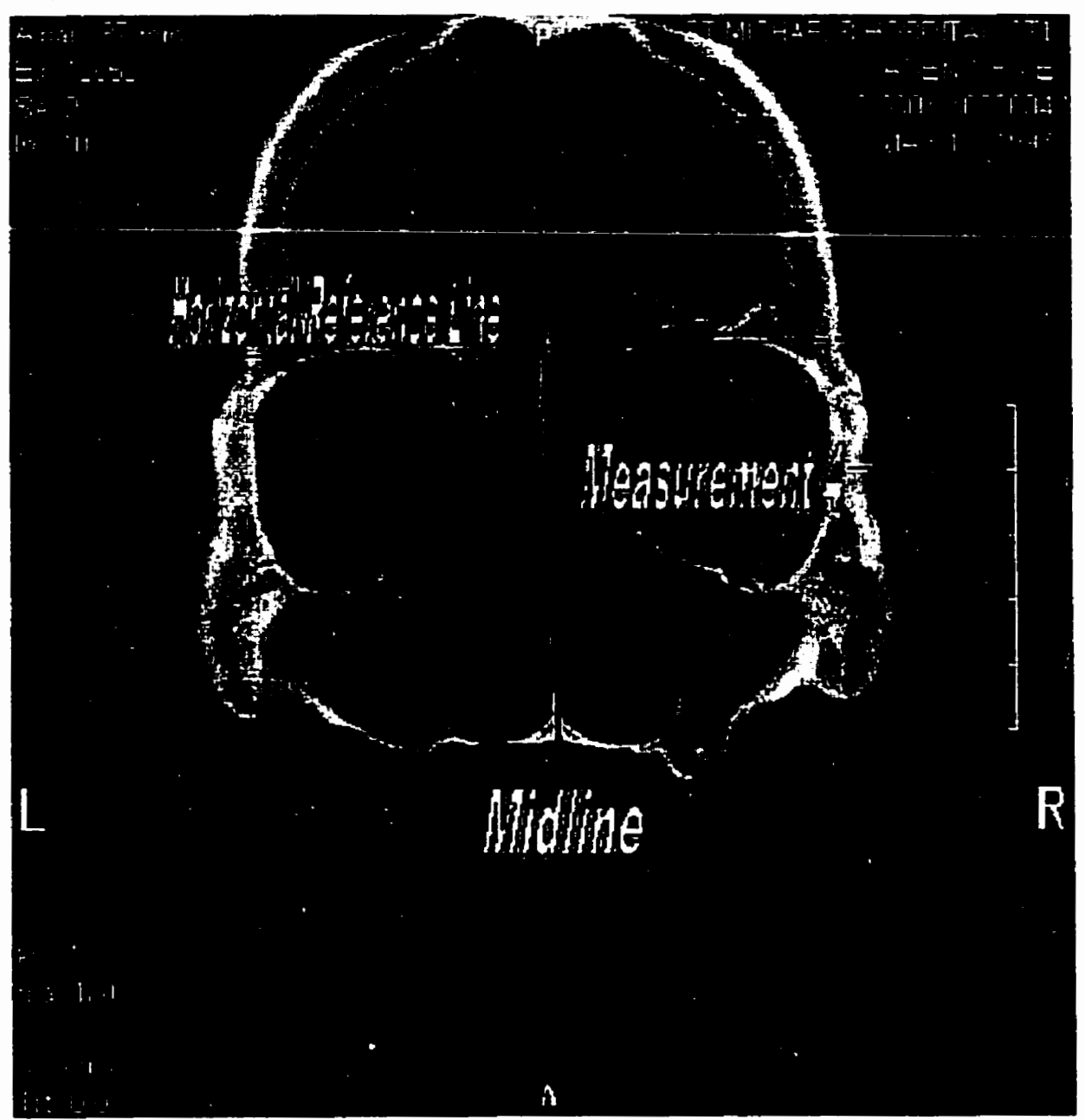




\section{DECLARATION OF FUNDING}

This project was funded by grants from the A.O/A.S.I.F. Foundation, Switzerland and The Division of Plastic \& Reconstructive Surgery, St. Michael's Hospital, Canada 


\section{APPENDIX A - RAW DATA MEASUREMENT 1}

\begin{tabular}{|c|c|c|c|c|c|c|c|c|c|c|c|c|}
\hline & & MEASUR & $\begin{array}{l}\text { EMENTI } \\
\text { OBSERV }\end{array}$ & $\begin{array}{l}\text { I(POSTER } \\
\text { /ER] }\end{array}$ & IOR ZYG & OMATIC & ARCH WI & IDTH) & OBSERVI & IER2 & & \\
\hline & obsl & $\begin{array}{l}\text { LEFT } \\
\text { obs2 }\end{array}$ & obs3 & obsl & $\begin{array}{l}\text { RJGHT } \\
\text { obs2 }\end{array}$ & obs3 & obs! & $\begin{array}{l}\text { LEFT } \\
\text { obs2 }\end{array}$ & obs3 & obsl & $\begin{array}{l}\text { RJGHT } \\
\text { obs2 }\end{array}$ & obs3 \\
\hline SKULLI & 65.77 & 65.31 & 66.39 & 64.9 & 63.08 & 64.03 & $\quad 66.44$ & 66.92 & $\quad 66.51$ & 65.05 & $\quad 65.09$ & 64.54 \\
\hline can 1 & 67 & 67 & 66 & 64 & 64 & 65 & 68 & 68 & 68 & 63 & 64 & 63 \\
\hline reposition I & 66 & 66 & 67 & 65 & 65 & 64 & 67 & 67 & 67 & 65 & 65 & 65 \\
\hline no change & 66 & 67 & 67 & 65 & 64 & 64 & 67 & 66 & 67 & 65 & 65 & 65 \\
\hline gantry 5 & 66 & 67 & 67 & 64 & 64 & 64 & 67 & 67 & 67 & 65 & 65 & 65 \\
\hline gantry 10 & 67 & 67 & 67 & 64 & 64 & 64 & 68 & 67 & 68 & 65 & 65 & 65 \\
\hline gantry 15 & 67 & 67 & 67 & 65 & 65 & 65 & 67 & 67 & 67 & 65 & 66 & 66 \\
\hline gantry 20 & 66 & 65 & 66 & 64 & 64 & 64 & 67 & 67 & 67 & 67 & 66 & 66 \\
\hline inclination 5 & 67 & 66 & 66 & 65 & 66 & 65 & 67 & 67 & 67 & 66 & 67 & 66 \\
\hline inclination 10 & 70 & 68 & 68 & 65 & 65 & 65 & 67 & 65 & 66 & 66 & 66 & 66 \\
\hline $\begin{array}{l}\text { inclination } 15 \\
\text { inclination } 20\end{array}$ & $\begin{array}{l}\text { landmark } \\
\text { landmark }\end{array}$ & $\begin{array}{l}\text { (s unidentif } \\
\text { \&s unidentif }\end{array}$ & $\begin{array}{l}\text { iable } \\
\text { iable }\end{array}$ & & & & & & & & & \\
\hline rigid fixation & 68 & 67 & 67 & 64 & 64 & 64 & 67 & 66 & 67 & 65 & 64 & 65 \\
\hline SKULL2 & 61.82 & 62.16 & 62.33 & 61.85 & 62.18 & 61.72 & 63.7 & 63.74 & 63.3 & 63.54 & 62.51 & 63.47 \\
\hline scan & 63 & 64 & 65 & 64 & 63 & 62 & 63 & 65 & 64 & 64 & 63 & 64 \\
\hline SKULL3 & 60.5 & 61.25 & 61.54 & 61.67 & 60.96 & 61.92 & 61.58 & 61.63 & 61.87 & 62.43 & 61.82 & 61.86 \\
\hline scan 3 & 60 & 60 & 60 & 63 & 63 & 64 & 62 & 61 & 60 & 62 & 63 & 63 \\
\hline SKULL4 & 58.47 & 58.73 & 58.36 & 58.38 & 58.66 & 59.16 & 59.81 & 58.21 & 58.78 & 60.52 & 59.88 & 59.66 \\
\hline $\operatorname{scan} 4$ & 57 & 57 & 58 & 61 & 61 & 61 & 58 & 58 & 58 & 61 & 61 & 61 \\
\hline
\end{tabular}




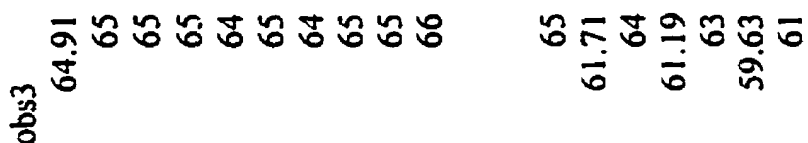

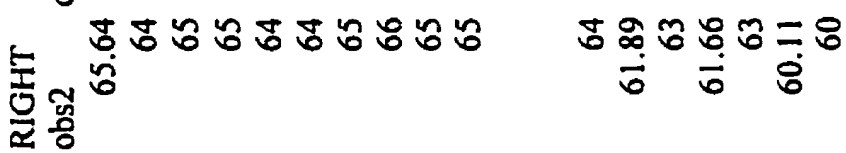

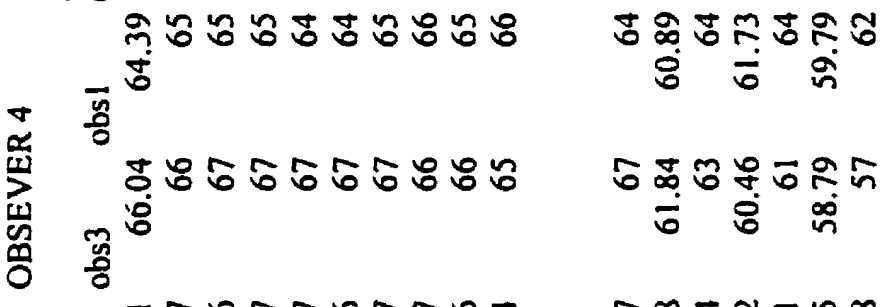

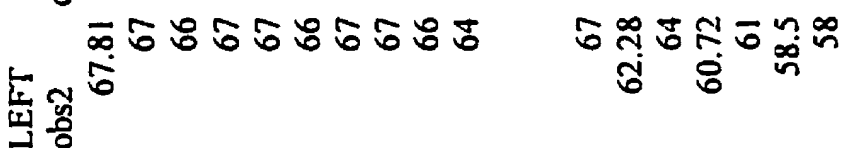

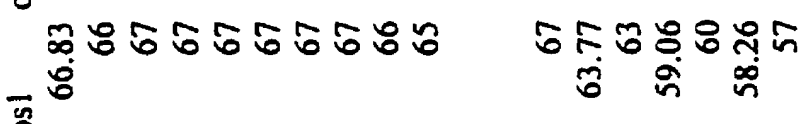

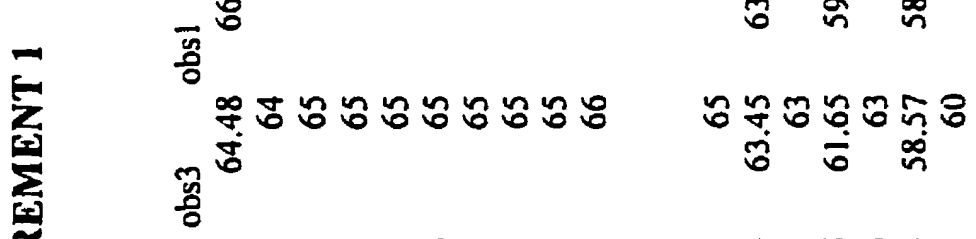

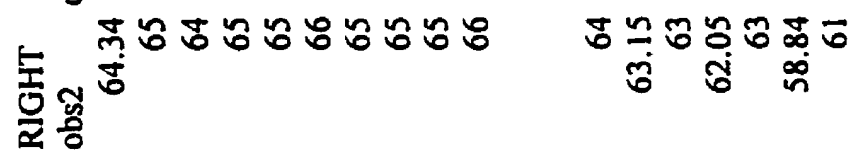

$$
\begin{aligned}
& \text { 这 施 }
\end{aligned}
$$

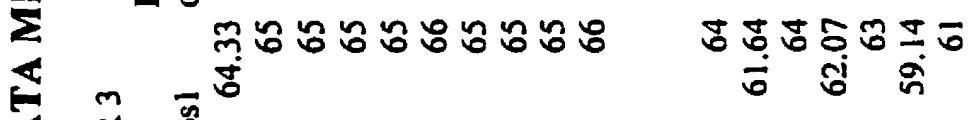

$$
\begin{aligned}
& \text { 胥 }
\end{aligned}
$$



$$
\begin{aligned}
& 4 \\
& \text { 衰罍 } \\
& \text { خ } \\
& \text { कू }
\end{aligned}
$$




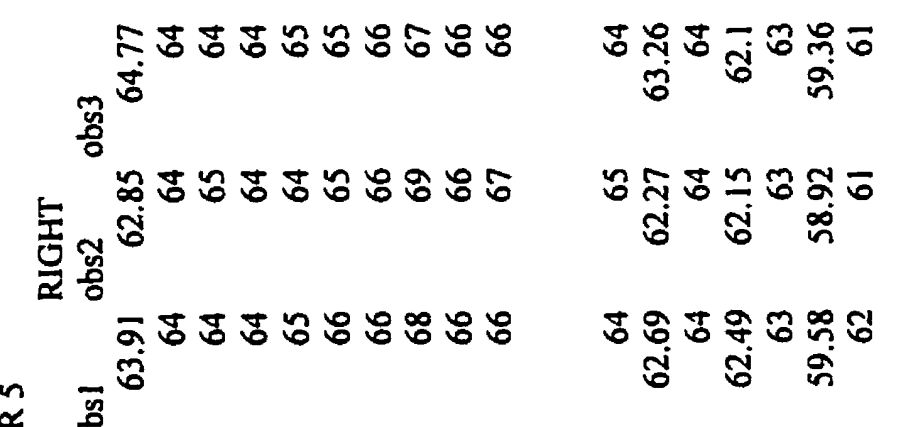

욤

三各

호ํํํ요요

《

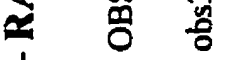

$\frac{1}{2}$

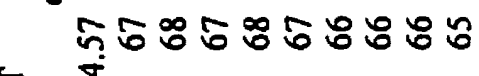

窇

กิ่

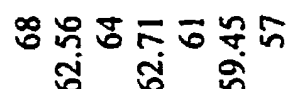

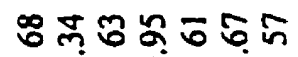

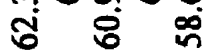




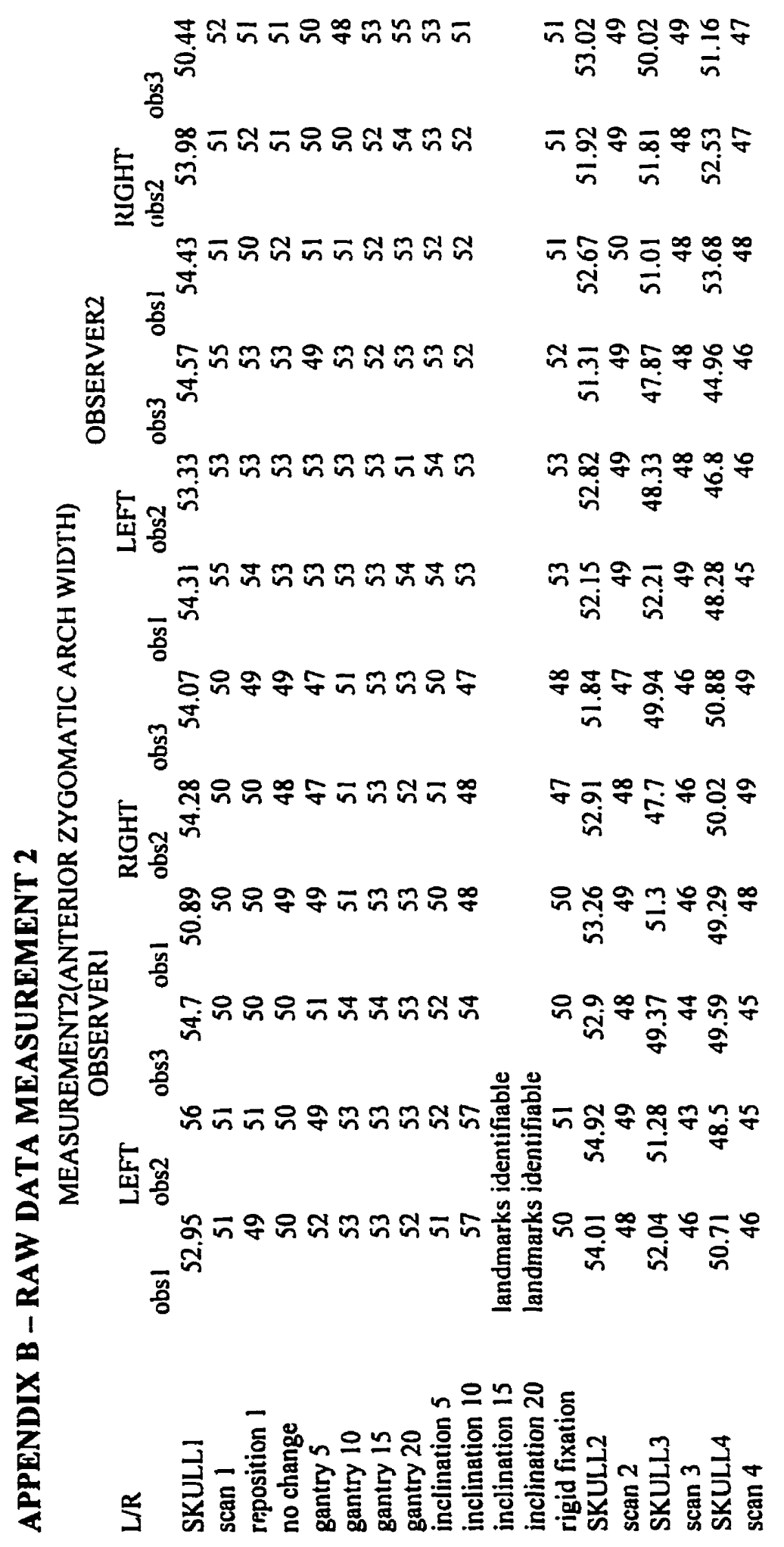




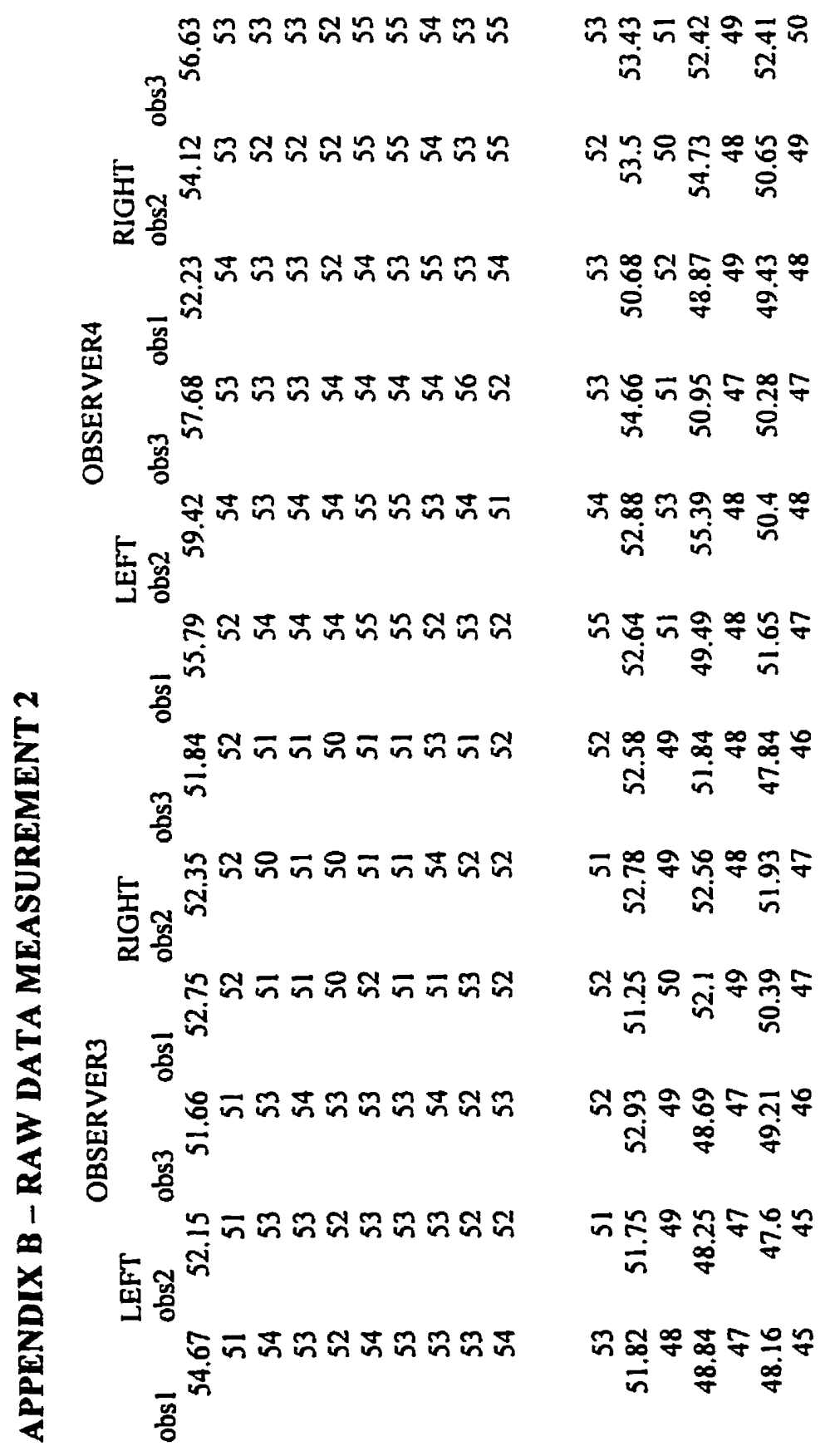




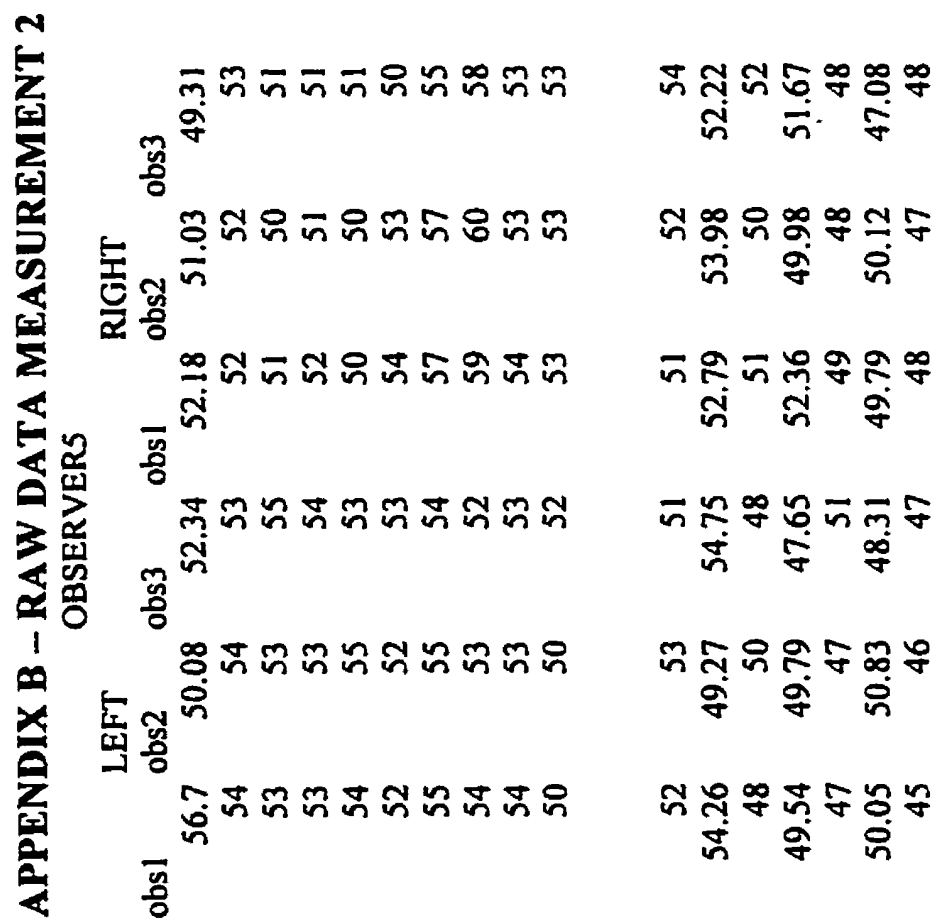


APPENDIX C - RAW DATA MEASUREMENT 3

MEASUREMENT3(ZYGOMATIC ARCH PROJECTION)

\begin{tabular}{|c|c|c|c|c|c|c|c|c|c|c|c|c|}
\hline \multirow{3}{*}{ L/R } & \multicolumn{5}{|c|}{ OBSERVERI } & \multicolumn{7}{|c|}{ OBSERVER2 } \\
\hline & & \multirow{2}{*}{$\begin{array}{l}\text { LEFT } \\
\text { obs2 }\end{array}$} & & \multirow[b]{2}{*}{ obs! } & \multirow{2}{*}{$\begin{array}{l}\text { RIGHT } \\
\text { obs2 }\end{array}$} & \multirow[b]{2}{*}{ obs 3} & \multirow[b]{2}{*}{ obsl } & LEFT & & \multirow[b]{2}{*}{ obsl } & RIGHT & \\
\hline & obsl & & obs3 & & & & & obs 2 & obs3 & & obs2 & obs3 \\
\hline SKULLI & 42.98 & 40.49 & 40.47 & 39.86 & 35.74 & 38.34 & 38.34 & 39.45 & 35.36 & 33.26 & 40.28 & 42.18 \\
\hline scan 1 & 46 & 46 & 47 & 49 & 48 & 48 & 41 & 41 & 42 & 45 & 44 & 45 \\
\hline reposition 1 & 48 & 45 & 45 & 50 & 50 & 51 & 40 & 39 & 41 & 50 & 48 & 48 \\
\hline no change & 46 & 45 & 46 & 50 & 50 & 50 & 39 & 42 & 41 & 48 & 48 & 46 \\
\hline gantry 5 & 44 & 47 & 45 & 48 & 50 & 50 & 40 & 40 & 45 & 45 & 46 & 47 \\
\hline gantry 10 & 42 & 42 & 40 & 45 & 44 & 46 & 40 & 39 & 40 & 46 & 47 & 46 \\
\hline gantry 15 & 41 & 42 & 39 & 42 & 43 & 43 & 40 & 39 & 40 & 42 & 46 & 44 \\
\hline gantry 20 & 42 & 42 & 42 & 45 & 45 & 44 & 35 & 41 & 38 & 44 & 43 & 40 \\
\hline inclination 5 & 51 & 47 & 47 & 49 & 48 & 50 & 34 & 35 & 36 & 47 & 47 & 48 \\
\hline inclination 10 & 40 & 43 & 45 & 49 & 51 & 52 & 35 & 38 & 40 & 47 & 45 & 48 \\
\hline $\begin{array}{l}\text { inclination } 15 \\
\text { inclination } 20\end{array}$ & $\begin{array}{l}\text { landmarks } \\
\text { landmarks }\end{array}$ & $\begin{array}{l}\text { s unidentif } \\
\text { s unidentif }\end{array}$ & $\begin{array}{l}\text { fiable } \\
\text { fiable }\end{array}$ & & & & & & & & & \\
\hline rigid fixation & 48 & 48 & 48 & 46 & 51 & 49 & 42 & 43 & 43 & 46 & 47 & 50 \\
\hline SKULL2 & 30.36 & 29.39 & 33.02 & 24.49 & 28.51 & 31.32 & 37.23 & 35.48 & 32.73 & 37.67 & 35.03 & 35.85 \\
\hline $\operatorname{scan} 2$ & 41 & 39 & 42 & 44 & 43 & 41 & 40 & 40 & 42 & 40 & 40 & 43 \\
\hline SKULL3 & 38.3 & 36.89 & 38.38 & 34.93 & 36.28 & 39.53 & 34.43 & 35.45 & 38.78 & 38.34 & 39.31 & 35.18 \\
\hline $\operatorname{scan} 3$ & 43 & 47 & 44 & 46 & 49 & 49 & 39 & 39 & 35 & 44 & 41 & 41 \\
\hline SKULL4 & 30.82 & 34.57 & 34.02 & 33.83 & 36.07 & 36.12 & 29.73 & 30.06 & 31.14 & 33.64 & 36.6 & 36.64 \\
\hline $\operatorname{scan} 4$ & 39 & 37 & 36 & 41 & 39 & 38 & 43 & 43 & 43 & 41 & 41 & 39 \\
\hline
\end{tabular}




\section{APPENDIX C - RAW DATA MEASUREMENT 3}

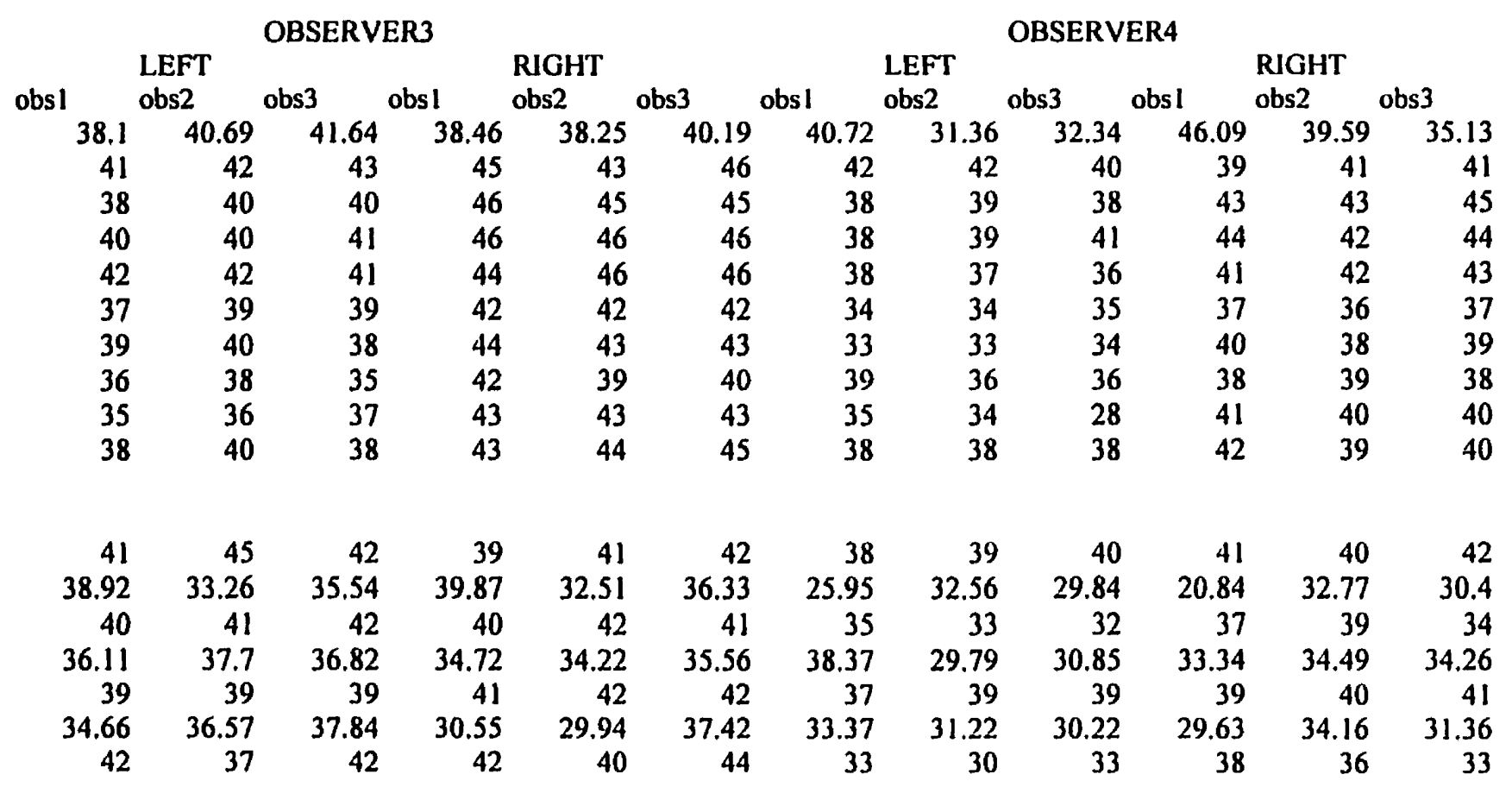




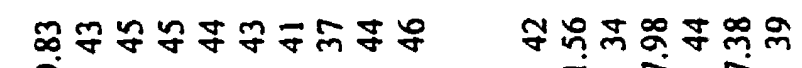

$$
\begin{aligned}
& \text { กิ้ }
\end{aligned}
$$

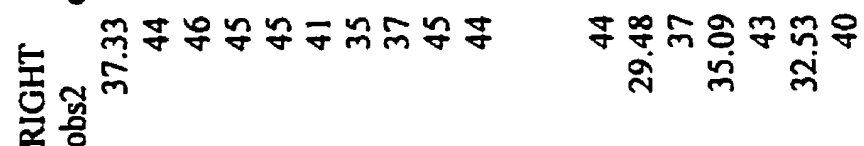

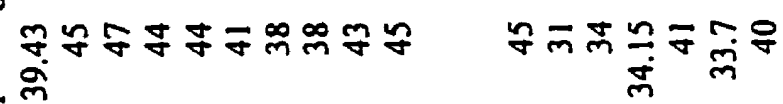

$$
\begin{aligned}
& \text { 苾 }
\end{aligned}
$$

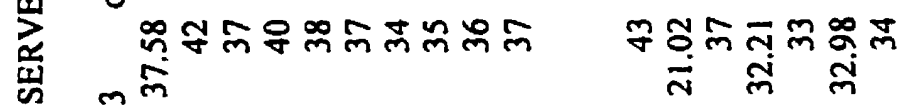

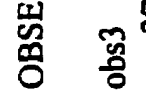

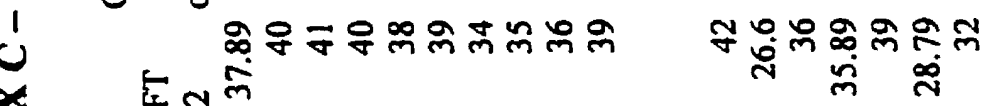

$$
\begin{aligned}
& \text { 놇 }
\end{aligned}
$$

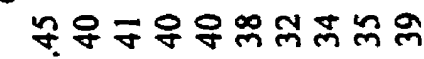

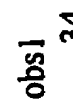

$$
\begin{aligned}
& \text { ชุำ }
\end{aligned}
$$$$
\frac{z_{2}}{2}
$$ 
APPENDIX D - RAW DATA MEASUREMENT 4

MEASUREMENT4(ZYGOMATIC ARCH HEIGHT)

\begin{tabular}{|c|c|c|c|c|c|c|c|c|c|c|c|c|}
\hline \multirow{3}{*}{ L/R } & \multicolumn{5}{|c|}{ OBSERVERI } & \multicolumn{7}{|c|}{ OBSERVER2 } \\
\hline & & LEFT & & & RIGHT & & & LEFT & & & RIGHT & \\
\hline & obsl & obs2 & obs3 & obs 1 & obs2 & obs 3 & obs I & obs2 & obs 3 & obsl & obs2 & obs 3 \\
\hline SKULLI & 44.39 & 45.09 & 41.1 & 39.03 & 40.31 & 38.87 & 40.46 & 46.58 & 42.07 & 41.82 & 43.08 & 41.38 \\
\hline scan 1 & 42 & 42 & 42 & 41 & 40 & 41 & 42 & 42 & 42 & 41 & 42 & 43 \\
\hline reposition I & 43 & 43 & 43 & 42 & 43 & 42 & 43 & 44 & 43 & 42 & 42 & 42 \\
\hline no change & 41 & 42 & 42 & 43 & 43 & 43 & 43 & 44 & 43 & 42 & 42 & 43 \\
\hline gantry 5 & 42 & 42 & 42 & 43 & 43 & 42 & 43 & 42 & 42 & 44 & 44 & 44 \\
\hline gantry 10 & 40 & 39 & 39 & 38 & 40 & 40 & 42 & 42 & 42 & 43 & 42 & 42 \\
\hline gantry 15 & 43 & 42 & 43 & 41 & 42 & 42 & 42 & 43 & 43 & 42 & 42 & 41 \\
\hline gantry 20 & 42 & 42 & 43 & 42 & 42 & 41 & 42 & 43 & 44 & 42 & 42 & 43 \\
\hline inclination 5 & 43 & 42 & 42 & 42 & 43 & 42 & 42 & 42 & 43 & 43 & 44 & 44 \\
\hline inclination 10 & 43 & 44 & 44 & 43 & 43 & 43 & 44 & 44 & 44 & 43 & 43 & 44 \\
\hline $\begin{array}{l}\text { inclination } 15 \\
\text { inclination } 20\end{array}$ & $\begin{array}{l}\text { landmark: } \\
\text { landmarks }\end{array}$ & $\begin{array}{l}5 \text { unidentif } \\
s \text { unidentif }\end{array}$ & $\begin{array}{l}\text { fiable } \\
\text { fiable }\end{array}$ & & & & & & & & & \\
\hline rigid fixation & 42 & 43 & 43 & 42 & 43 & 42 & 43 & 42 & 43 & 43 & 42 & 43 \\
\hline SKULL2 & 42.38 & 40,88 & 35.11 & 36.71 & 36.3 & 38.3 & 39.99 & 39.94 & 42.13 & 36.65 & 42.15 & 40.35 \\
\hline $\operatorname{scan} 2$ & 45 & 45 & 44 & 43 & 43 & 42 & 44 & 44 & 44 & 46 & 47 & 48 \\
\hline SKULL3 & 34.65 & 38.71 & 40.25 & 35.67 & 35.75 & 35.9 & 39.79 & 41.95 & 42.88 & 40.32 & 40.79 & 41.61 \\
\hline $\operatorname{scan} 3$ & 46 & 46 & 47 & 43 & 43 & 42 & 46 & 47 & 47 & 42 & 42 & 42 \\
\hline SKULL4 & 39.41 & 39.94 & 36.36 & 38.47 & 37.25 & 39.55 & 40.9 & 38.34 & 41.58 & 40.5 & 40.15 & 40.06 \\
\hline $\operatorname{scan} 4$ & 42 & 42 & 42 & 39 & 40 & 39 & 41 & 41 & 42 & 40 & 39 & 40 \\
\hline
\end{tabular}




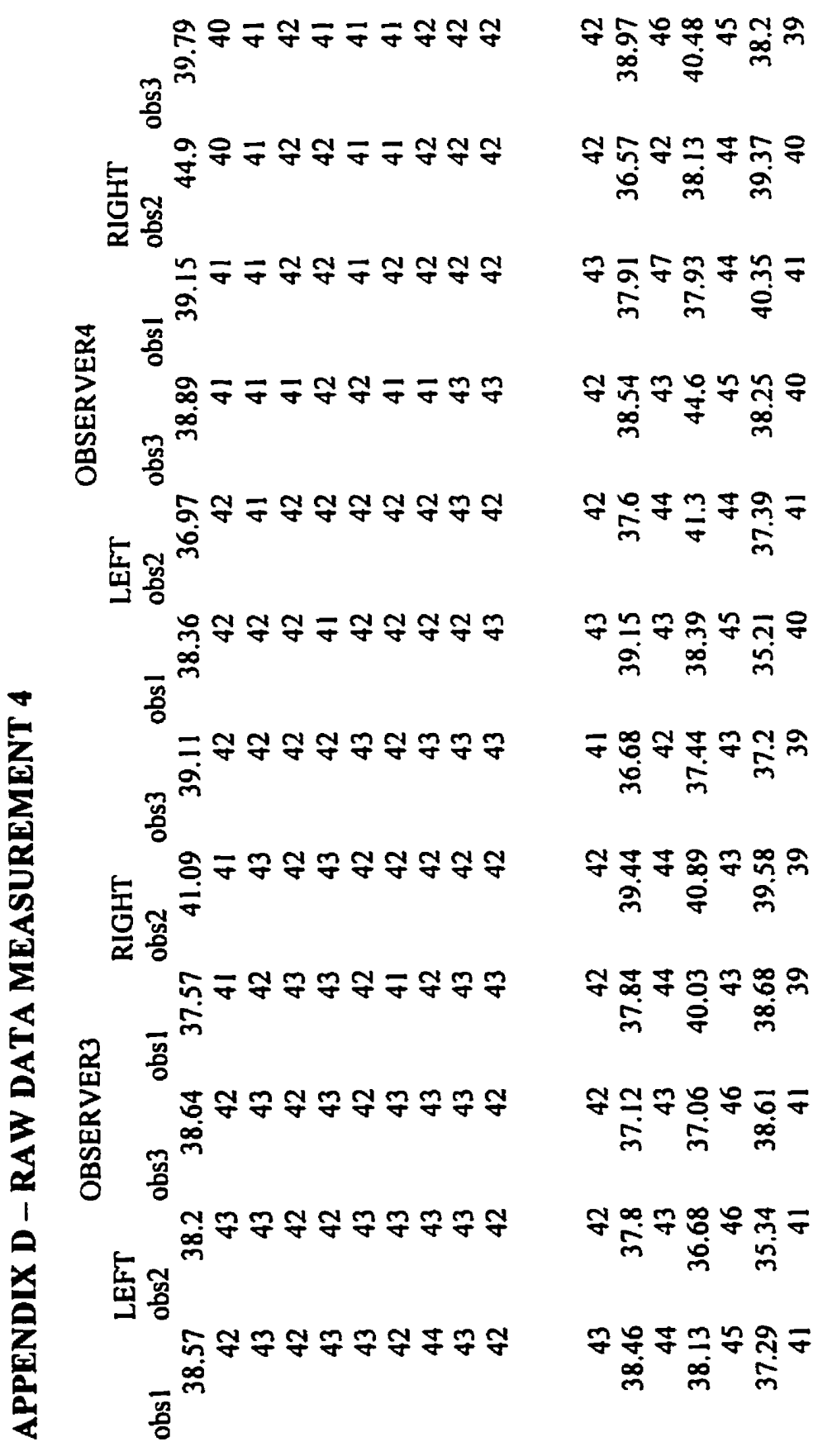




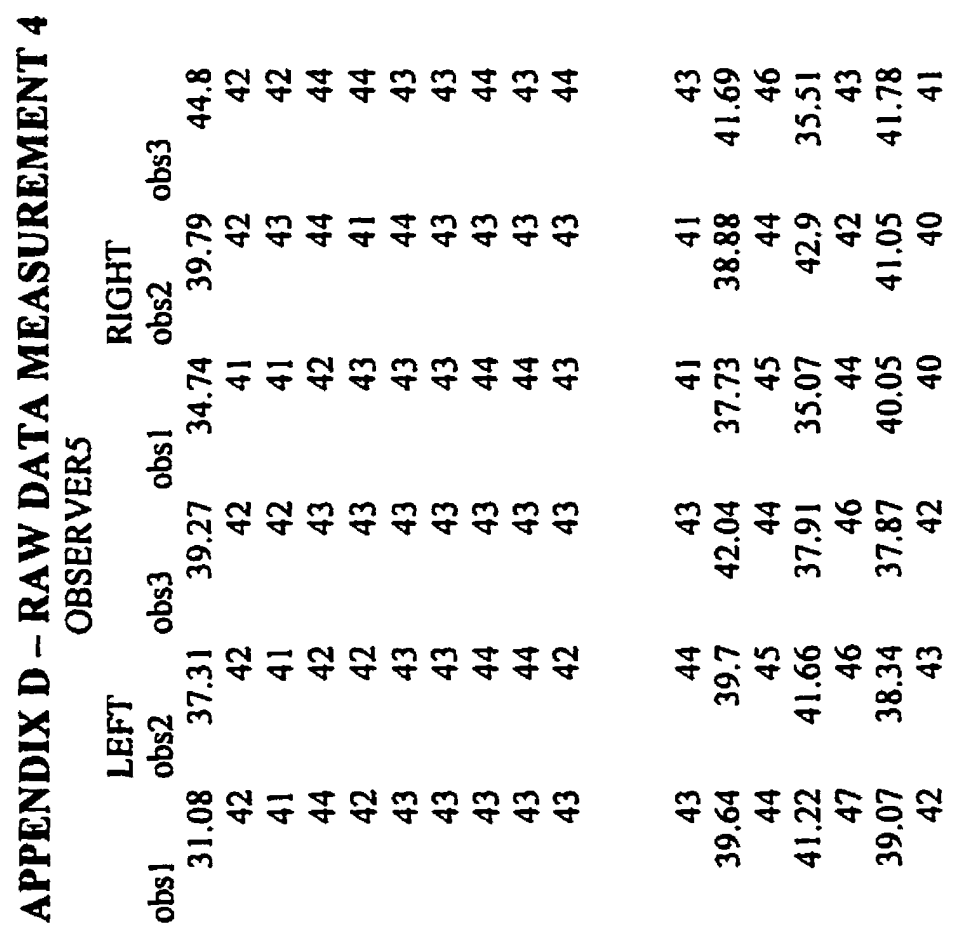




\section{REFERENCES}

1. LeFort R. Étude expérimentale sur les fractures de la machoire supèieuere. Rev Chir 23: 208-227, 360-379, 479-507, 1901 as quoted in Haug RH, Indresano AT. Management of Maxillary Fractures in Oral \& Maxillofacial Surgery. Peterson LJ, Indresano AT, Marciani RD, Roser SM. JB Lippincott Co. Philidelphia. Vol 1, pp 469, 1992.

2. Morgan BD, Madan DK, Bergerot JP: Fractures of the middle third of the face-a review of 300 cases. Br J Plast Surg 25:147,1972

3. Turvey TA: Midfacial fractures: A retrospective analysis of 593 cases. J Oral Surg 35:887, 1977.

4. Afzelius L, Rosén C: Facial fractures. A review of 368 cases. Int J Oral Surg 9:25, 1980.

5. Lundin K, Ridell A, Sandberg N, Ohman A: One thousand maxillo-facial and related fractures at the ENT-Clinic in Gothenburg. A two-year prospective study. Acta Otolaryngol 75:359, 1973.

6. Gillies HD, Kilner TP, Stone D: Fractures of the malar-zygomatic compound, with a description of a new X-ray position. $\mathrm{Br} J$ Surg 14:651, 1927 as quoted in Oral \& Maxillofacial Trauma. Edited by Fonseca RJ, Walker RV. Saunders Co. Philadelphia, pp $1251,1991$.

7. Keen WW: Surgery: Its Principles and Practice. Philadelphia, WB Saunders Company, 1909 as quoted in Oral \& Maxillofacial Trauma Edited by Fonseca RJ, Walker RV. Saunders Co. Philadelphia, pp 1251, 1991.

8. Pozatek ZW, Kaban LB, Guralnick WC: Fractures of the zygomatic complex: An evaluation of surgical management with special emphasis on the eyebrow approach. J Oral Surg 31:141, 1973.

9. Lothrop HA: Fractures of the superior maxillary bone caused by direct blows over the malar bone. Boston Med Surg J 154:8, 1906 as quoted in Oral \& Maxillofacial Trauma. Edited by Fonseca RJ, Walker RV. Saunders Co. Philadelphia, pp 1251, 1991.

10. Strohmeyer L: Handbuch der Chirurgie. Vol. 1. Freiburg, Switzerland, 1844 as quoted in Oral \& Maxillofacial Trauma. Edited by Fonseca RJ, Walker RV. Saunders Co. Philadelphia, pp 1251, 1991.

11. Banovetz JD, Duvall AJ: Zygomatic fractures. Otol Clin North Am 9:499, 1976.

12. Knight JS, North JF: The classification of malar fractures: An analysis of displacement as a guide to treatment. Br J Plast Surg 13: 325, 1961.

13. Gruss JS, MacKinnon SE: Complex maxillary fractures: Role of buttress reconstruction and immediate bone grafts. Plast Reconstr Surg 78: 9, 1987. 
14. Souyris F, Klersy F, Jammet P, Payrot C.: Malar bone fractures and their sequelae: A statistical study of 1393 cases covering a period of 20-years. J Craniomaxillofac Surg 17:64, 1989.

15. Brown JB, Fryer MP, Mcdowell F: Internal wire fixation for fractures of upper jaw, orbit, zygoma and severe facial crushes. Plast Reconstr Surg 9: 276, 1952 as quoted in Oral \& Maxillofacial Trauma. Edited by Fonseca RJ, Walker RV. Saunders Co. Philadelphia, pp $1251,1991$.

16. Gratz KW, Gensheimer TH, Spiessl B: External cranial fixation for severe maxillofacial injuries. Akt Traumatol 14: 259, 1984 as quoted in Oral \& Maxillofacial Trauma. Edited by Fonseca RJ, Walker RV. Saunders Co. Philadelphia, pp 1251, 1991.

17. Kim YO: Transcutaneous reduction and extrnal fixation for the treatment of noncomminuted zygoma fractures. J Oral Maxillofac Surg 56: 1382, 1998

18. Adams WM: Internal wiring fixation of facial fractures. Surgery 12: 523,1942 as quoted in Oral \& Maxillofacial Trauma. Edited by Fonseca RJ, Walker RV. Saunders Co. Philadelphia, pp 1251, 1991.

19. Champy M, Lodde JP, Muster D, Grasset D: Osteosynthesis using miniaturized screwon plates in facial and cranial surgery. Ann Chir Plast Esthet 22: 261, 1977 as quoted in Oral \& Maxillofacial Trauma. Edited by Fonseca RJ, Walker RV. Saunders Co. Philadelphia, pp $1251,1991$.

20. Rohrich RJ, Watumull D: Comparison of rigid plate versus wire fixation in the management of zygoma fractures: A long-term follow-up clinical study. Plast Reconstr Surg 96:570,1995.

21. Ellis E III, Kittidumkerng W: Analysis of treatment for isolated zygomaticomaxillary complex fractures. J Oral Maxillofac Surg 54:386, 1996.

22. Manson PN, Markowitz B, Mirvis S, Dunham M, Yaremchuk M: Toward CT based facial fracture treatment. Plast Reconstr Surg 85:202, 1990.

23. Russell JL, Davidson MJC, Daly BD, Corrigan: Computed tomography in the diagnosis of maxillofacial trauma. Br J Oral Maxillofac Surg 28:287, 1990.

24. Finkle Dr, Ringler SL, Luttenton CR, Beernink JH, Peterson NT, Dean RE: Comparison of the diagnostic methods used in maxillofacial trauma. Plas \& Recon Surg 75:32, 1985.

25. Gentry LR, Manor WF, Turski PA, Strother CM: High-resolution CT analysis of facial struts in trauma: 2. Osseous and soft-tissue complication. AJR 140:533, 1983.

26. Levy RA, Kelman RM, Rosenbaum AE: The effect of computed tomographic scan orientation on information loss in the three-dimensional reconstruction of tripod zygomatic fractures. Inves Radio 26:427, 1991. 
27. Henmy DC, Tessier PL: CT of dry skulls with craniofacial deformities: Accuracy of three-dimensional reconstruction. Radiology 157:113, 1985.

28. Hahn FJ, Chu WK, Cheung JY: CT measurements of cranial growth: Alternative measurement method. Amer J Neuroradiol 6:537, 1985.

29. Christiansen EL, Thompson $\mathrm{R}$, Kipp S: Intra- and inter-observer variability and accuracy in the determination of linear and angular measurements in computed tomography. An in vitro and in situ study of human mandibles. Acta Odontol Scan 44:221, 1986.

30. Matteson SR, Bechtold W, Phillips C, Staab EV: A method for Three-dimensional image reformation for quantitative cephalometric analysis. J Oral Maxillofac Surg 47:1053, 1989.

31. Tjan CF: Computed Tomography: A three-dimensional approach to craniofacial measurements. Thesis, submitted in partial fulfillment of the requirements for the Degree of Master of Science, Faculty of Dentistry, University of Toronto. 1994.

32. Waitzman AA, Posnick JC, Armstrong DC, Pron GE: Craniofacial skeletal measurements based on computed tomography: Part I. Accuracy and reproducibility. Cleft Palate-Craniofac J 29:112. 1992.

33. Waitzman AA, Posnick JC, Armstrong DC, Pron GE: Craniofacial skeletal measurements based on computed tomography. Part II. Normal values and growth trends. Cleft Palate-Craniofac J 29:118, 1992.

34. Posnick JC, Goldstein JS, Waitzman AA, Armstrong DC: Surgical correction of the Treacher Collins malar deficiency with quantitative CT scan analysis of long-tern results. Plast Reconstr Surg 92:12, 1993.

35. Posnick JC, Lin KY, Chen P, Armstrong DC: Sagittal synostosis: Quantitative assessment of presenting deformity and surgical results based on CT scans. Plast Reconstr Surg 92:1015, 1993.

36. Posnick JC, Lin KY, Chen P, Armstrong DC: Metopic synostosis: Quantitative assessment of presenting deformity and surgical results based on CT scans. Plast Reconstr Surg 93:16, 1994.

37. Posnick JC, Lin KY, Ghawar BJ, Armstrong DC: Crouzon syndrome: Quantitative assessment of presenting deformity and surgical results based on CT scans. Plast Reconstr Surg 92:1027, 1993.

38. Posnick JC, Lin KY, Ghawar BJ, Armstrong DC: Apert syndrome: Quantitative assessment by $C T$ scan of presenting deformity and surgical results after first stage reconstruction. Plast Reconstr Surg 93:489, 1994. 
39. Honda $\mathrm{H}$, Watanabe $\mathrm{K}$, Kusumoto $\mathrm{S}$ : Optimal positioning for $\mathrm{CT}$ examinations of the skull base. Europ J Radiol 7:225, 1987.

40. Bayley JC, Kruger DM, Schlegel JM: Does the angle of the computed tomographic scan change spinal canal measurements. Spine 16(Supp1):S526,1991.

41. Fiala TGS, Novelline RA, Yaramchuk MJ: Comparison of CT imaging artifacts from craniomaxillofacial internal fixation devices. Plast Reconstr Surg 92:1227,1993.

42. Sullivan PK, Smith JF, Rozzelle AA: Cranio-orbital reconstruction: Safety and image quality of metallic implants on CT and MRI scanning. Plast Reconstr Surg 94:589, 1994.

43. Eppley BL, Sparks C, Herman E, Edwards M, McCarty M, Sadove AM: Effects of skeletal fixation on craniofacial imaging. J Craniofac Surg 4:67, 1993.

44. Barone $\mathrm{CM}$, Eisig $\mathrm{S}$, Wallach $\mathrm{S}$, Mednick $\mathrm{R}$ : Effects of rigid fixation device composition on three-dimensional computed axial tomography imaging: Direct measurements on a pig model. J Oral Maxillfac Surg 52:737, 1994.

45. Anastakis DJ, Antonyshyn OM, Cooper PW, Yaffe MJ, Bush K, Mawdsley GE: Computed tomography artifact associated with craniofacial fixation devices: An experimental study. Ann Plast Surg. 37:349, 1996.

46. Farkas LG: Anthropometry of the Head and Face. $2^{\text {nd }}$ ed. Raven Press, New York, $405 \mathrm{pp}, 1994$.

47. Ferrairo VF, Sforza C, Poggio CE, Schmitz JH: Craniofacial growth: A threedimensional soft-tissue study from 6 years to adulthood. J Craniofac Genet Dev Biol 18:138, 1998.

48. Nechala P, Mahoney J, Farkas LG: Maxillozygional anthropometric landmark: a new morphometric orientation point in the upper face. Ann Plast Surg 41:402, 1998.

49. Peck S, Peck L, Kaaja M: Skeletal asymmetry in esthetically pleasing faces. The Angle Orthodontist 61:43, 1991. 